\title{
Social evolution theory: a review of methods and approaches
}

\author{
Tom Wenseleers, Andy Gardner and Kevin R. Foster
}

\section{Overview}

Over the past decades much progress has been made in understanding the evolutionary factors that can promote social behaviour. Nevertheless, the bewildering range of methods that have been employed leave many confused. Here we review some of the major approaches that can be used to model social evolution, including the neighbour-modulated fitness, inclusive fitness and multilevel selection methods. Through examples we show how these different methodologies can yield complementary insight into the evolutionary causes of social behaviour, and how, for a wide range of problems, one method can be translated into the other without affecting the final conclusion. We also review some recent developments, such as the evolution of cooperation in spatial settings and networks, and multilocus extensions of the theory, and discuss some remaining challenges in social evolution theory.

\subsection{The puzzle of altruism}

Individuals sometimes give up resources to benefit their neighbours, to the extent that this helping lowers the individual's reproductive fitness. Such altruistic traits (Table 6.1) pose a difficulty for Darwin's theory of natural selection, which emphasises the spread of individually advantageous traits (Darwin 1859). Yet altruism abounds in the natural world, and is observed in settings as diverse as bacteria (Chapter 13), multicellular organisms with specialised non-reproductive tissues (Michod 1999, Strassmann \& Queller 2007), social insects with a sterile worker caste (Bourke \& Franks 1995, Ratnieks et al. 2006, Ratnieks \& Wenseleers 2008), and, of course, human society (Chapter 15; Gintis et al. 2005). Thus, altruism poses a major problem for evolutionary theory.

Formal attempts to solve the puzzle of altruism have a long history, going back at least to Darwin (reviewed in Dugatkin \& Reeve 1994, Gardner \& Foster 2008). The major breakthrough in cracking the problem, however, only came in the 1960s with the formulation of Hamilton's $(1963,1964)$ theory of inclusive fitness (later dubbed kin selection: Maynard Smith 1964). This showed that altruism is selectively favoured if $b . r>c$, where $c$ is the personal fitness cost to the actor, $b$ is the personal fitness benefit to the recipient, and $r$ is the genetic relatedness between actor and recipient, an

Social Behaviour: Genes, Ecology and Evolution, ed. Tamás Székely, Allen J. Moore and Jan Komdeur. Published by Cambridge University Press. @ Cambridge University Press 2010. 
Table 6.1. A classification of social behaviours, based on Hamilton $(1964,1970)$ and West et al. (2007a, 2007b). Fitness impact means the impact on direct fitness, which is the fitness that comes from personal reproduction

\begin{tabular}{|c|c|c|c|}
\hline & & \multicolumn{2}{|c|}{ Fitness impact on recipient } \\
\hline & & + & - \\
\hline $\begin{array}{l}\text { Fitness impact } \\
\text { on actor }\end{array}$ & $\begin{array}{l}+ \\
-\end{array}$ & $\begin{array}{l}\text { Mutual benefit } \\
\text { Altruism } \\
\text { Cooperation }\end{array}$ & $\begin{array}{l}\text { Selfishness } \\
\text { Spite } \\
\text { Competition }\end{array}$ \\
\hline
\end{tabular}

inequality that later become known as Hamilton's rule. The intuitive explanation is that when altruists help relatives reproduce this results in the indirect propagation of copies of the altruists' own genes, thereby enabling a gene for altruism to spread (Hamilton 1963, Dawkins 1976). Independently from Hamilton, however, others have taken a different approach and tried to solve the puzzle of altruism in terms of opposing selection within and between groups (Price 1972, Wilson 1975; for two early attempts see Wright 1945, Williams \& Williams 1957). These multilevel selection approaches later turned out to be just a different way of looking at the same problem, and in all cases resulted in the same conclusion as kin-selection models (Hamilton 1975, Wade 1980, Crow \& Aoki 1982, Queller 1992a, Dugatkin \& Reeve 1994, Wenseleers et al. 2003, Lehmann et al. 2007a). Unfortunately, this fact still does not seem to be universally acknowledged, as it is still all too common to see kin and group selection incorrectly being pitted against each other, and being presented as two different mechanisms that can promote cooperation (e.g. Gintis 2000a, Gintis et al. 2003, Fehr \& Fischbacher 2003, Wilson \& Hölldobler 2005, Nowak 2006, Traulsen \& Nowak 2006, Taylor \& Nowak 2007).

Even within the kin-selection tradition, some confusion remains, partly because Hamilton derived his theory from two different perspectives, based either on the concepts of neighbour-modulated fitness, which was just classical Darwinian fitness but taking explicit account of the social neighbourhood, and inclusive fitness, which extends the notion of Darwinian fitness to non-descendent offspring (Hamilton 1964, Taylor et al. 2007a, Gardner \& Foster 2008). These two perspectives, although generally giving the same result, differ in their interpretation of the benefit of altruism and of relatedness, which leads to the confusing situation that when people mention Hamilton's rule they do not always mean exactly the same thing (Frank 1997a). A large body of literature also exists on the appropriate definition of the cost, benefit and relatedness terms that make Hamilton's rule work in a population genetic sense (Michod \& Hamilton 1980, Queller 1984, 1992b, Frank 1997b).

The aim of this chapter is to show the formal relationship among the neighbour-modulated fitness, inclusive fitness and multilevel selection methods, and to show how, for a wide range of problems, one method can be translated into the other, without affecting the final conclusion. In addition, we will review some of the recent developments and remaining challenges in social evolution theory.

\subsection{Social evolution theory: methods and approaches}

\subsubsection{The Price equation}

Ultimately, given that evolution at its simplest level is a change in allele frequencies over time, all evolutionary theory has its basis in population genetics. Thus the traditional way of analysing social evolutionary models is to determine conditions, in terms of model parameters, for which genes encoding social traits can spread in the population (Cavalli-Sforza \& Feldman 1978, Charnov 1978, Uyenoyama \& Feldman 1980, Feldman \& Cavalli-Sforza 1981, Gayley 1993). Although this population genetic approach remains the gold standard, it has several disadvantages. First, it is tedious, involving processes such as the construction of mating tables, writing down recurrence equations and determining the conditions for gene spread - usually via matrix algebra (Bulmer 1994, Kokko 2007, Otto \& Day 2007). Second, such models generally require very specific assumptions, e.g. regarding the underlying genetic architecture of the trait, and hence they lack generality. Therefore there has been a need for the development of shortcut methods, which are both easier to apply 
and more general, but which are still solidly founded in population genetic theory. As we will show, a population genetic theorem known as the Price equation (Price 1970, 1972, 1995) provides the basis for several such shortcut methods. It also provides the foundation for a universally applicable theory of selection (Frank 1995a, Price 1995).

To start, consider a population containing $n$ entities indexed by $j$. These entities will usually be taken to be individuals, but as we will see they can also be genes within diploid genomes, cells, social groups or even species. Let $w_{j}$ be the absolute fitness of the jth entity, i.e. how many successful offspring entities it leaves in the next generation (this may also be a function of the probability of itself surviving to the next time period), and $v_{j}$ the fitness relative to the population average $\left(w_{j}, \bar{w}\right)$. In its simplest form, Price's theorem (Price $1970,1972)$ states that the average change in the value of some trait $z(\Delta \bar{z})$ from one generation to the next is given by

$\Delta \bar{z}=\operatorname{cov}\left(\frac{w_{j}}{\bar{w}}, z_{j}\right)+E\left(\frac{w_{j}}{\bar{w}} \Delta z_{j}\right)=\operatorname{cov}\left(v_{j}, z_{j}\right)+E\left(v_{j} \Delta z_{j}\right)$

Here, the terms cov and $E$ denote covariance (a measure of the statistical non-independence of two quantities; here, $v_{j}$ and $z_{i}$ ) and expectation (arithmetic average), both taken over all the entities in the population. The term $\Delta z_{j}$ is simply the change in the entity's trait value $z_{j}$ across a generation, i.e. between parent $\left(z_{j}\right)$ and offspring $\left(z_{j}^{\prime}\right)$, where $\Delta z_{j}=z_{j}^{\prime}-z_{j}$. In the standard case, the first term in equation 6.1 corresponds to the effects of selection (Price 1970, Frank 1995a, 1997b, 1998, Okasha 2006). To better understand this, we can, without loss of generality, decompose the covariance term into two separate components: a least-squares linear regression coefficient and a statistical variance $\left(\operatorname{cov}\left(v_{j}, z_{j}\right)=\beta_{v z}, V_{z}\right)$. Note that this transformation does not require that the relationship between the trait and relative fitness actually be linear. Instead, Price's great insight here was that a linear regression can be used to determine the net direction of change upon a trait across generations. Now, one can clearly see the effects of selection. The regression terms describe whether the trait of interest $z$ will increase or decrease the relative fitness $v$ of the focal entity, and the trait-variance term gives us the rate at which selection can act. This is intuitive: the more variability in the focal trait, the more fodder for the process of selection. The second term in equation 6.1, $E\left(v_{j} \Delta z_{j}\right)$, captures systematic biases in the transmission of the trait, for example due to biased mutation (see below).

Price's selection equation is very general (Price 1995, Frank 1995a), and applications are not limited to population genetics. Price's equation has been successfully applied to problems in epidemiology (Day \& Gandon 2007) and ecology (Loreau \& Hector 2001, Fox 2006), and even beyond the biological sciences. In economics, for example, $w_{j}$ might be the growth rates of businesses and $z_{j}$ some predictor of the firm's growth. In this case, the covariance term would describe selection among competing firms, and processes such as innovation could generate a positive covariance term and lead to positive selection (Andersen 2004). Many other applications exist, and links to standard population and quantitative genetic theory are given by Queller (1992b), Frank (1995a, 1997b, 1998), Wolf et al. (1999), Rice (2004), Okasha (2006) and Gardner et al. (2007). Page and Nowak (2002) also show how other equations for modelling evolutionary change - including the quasispecies equation, the replicator equation and the replicator-mutator equation - are all special cases of the Price equation.

For our purposes, however, we are interested in the genetic evolution of social behaviour (cultural evolution will be considered in section 6.3.5). In this instance the entities under consideration are normally individuals, $w$ is biological fitness, i.e. the number of successful offspring or gametes produced, and $z$ is usually defined as individual allele frequency $g$ at the locus that controls the social behaviour, or more formally breeding value. The concept of breeding value comes from quantitative genetics and is defined as the linear combination of the alleles across loci that best predicts an individual's phenotype (Falconer 1981, Crow \& Aoki 1982, Frank 1998). It is useful because not all effects of alleles will be inherited when there are interactions between focal alleles and the environment or alleles at other loci that may not be co-inherited (Chapters 1 and 2).

If we ignore mutation and genetic drift, and if we assume that in the case of diploid organisms meiosis is 
fair, the second term in equation 6.1, $E\left(v_{j} \Delta z_{j}\right)$, will be zero. Hence, the Price equation states that a gene coding for a social trait would spread when

$\Delta \bar{g}=\beta_{v g} \cdot V_{g}>0$

where the covariance is again written as the product of a regression $(\beta)$ and a variance $(V)$. Before Price, this equation was independently derived by Robertson (1966, 1968), who termed it the 'secondary theorem of natural selection. Given that genetic variance $\left(V_{g}\right)$ is always non-negative, equation 6.2 simply states that any response to selection will always be in the same direction as the regression of relative fitness on breeding value $\left(\beta_{v g}\right)$ and, because mean fitness will generally be a positive quantity $(\bar{w}>0)$, the condition for selection to favour an increase in average breeding value of the trait of interest can be written as $\beta_{w g}>0$. That is, genetic variance only affects the rate of selection, not its direction, so one can focus simply on the effects of a trait on fitness to predict whether the trait will be favoured by natural selection.

\subsubsection{Three equivalent methods for modelling social evolution}

The condition that $\beta_{w g}$ should be greater than zero provides a formal basis for explaining standard Darwinian adaptations, in which traits are selected for when they increase the fitness of their bearer. But how can it account for the evolution of altruistic behaviour that decreases individual fitness? As we will see, there are three main solutions to this problem: the neighbourmodulated fitness and inclusive fitness approaches that form the basis of kin selection theory, and also a levels-of-selection approach (Fig. 6.1). In many cases, these methods can be used interchangeably; they simply provide alternative ways for describing net gene frequency change.

\section{The neighbour-modulated fitness approach}

A first solution to the puzzle of altruism is based on the concept of neighbour-modulated fitness, first introduced by Hamilton (1964, 1970, 1975; see also
Queller 1992b, Taylor 1996, Taylor \& Frank 1996, Frank 1998, Rousset 2004, Taylor et al. 2007a). This captures the way in which a focal individual's personal fitness is a function of its own genotype (direct fitness effect) and also the genotypes of its social partners (indirect fitness effect), as illustrated in Figure 6.1a. That is, all fitness accounting is done through the effects on this focal individual, such that the fitness of an average recipient of the behaviour $(w)$ is expressed as a function of that individual's genotype or breeding value ( $g$, Falconer 1981) and the genotype of its social neighbours $\left(g^{\prime}\right)$. The neighbour-modulated fitness approach has often been referred to as an analysis of 'direct fitness', because of the way that fitness accounting is done through the effects on the personal reproduction of an average bearer of the altruistic genes. This makes it clear that a gene for altruism can only spread if the direct fitness of an average bearer increases.

First, assume that individuals interact in pairs, and that both individuals are identical in every respect other than their genotypes for the trait in question (Queller 1992b, Grafen 2006; extensions for interactions between individuals of different classes will be treated in section 6.3.1). In this case, an individual's neighbourmodulated fitness can be written as

$w=\bar{w}+\beta_{w g \cdot g^{\prime}} \cdot(g-\bar{g})+\beta_{w g^{\prime} \cdot g} \cdot\left(g^{\prime}-\bar{g}\right)$

where $\bar{w}$ and $\bar{g}$ are the average fitness and the average allele frequency of the individuals in the population, and the terms $(g-\bar{g})$ and $\left(g^{\prime}-\bar{g}\right)$ describe how the two individuals' genotypes depart from the population mean. The $\beta_{w g \cdot g^{\prime}}$ and $\beta_{w g^{\prime} \cdot g}$ terms separate out how these two genotypes affect the focal individual's fitness. Specifically, they are the least-squares partial regressions of the individual's fitness on its own and its partner's breeding values (Queller 1992b), where $\beta_{w g \cdot g^{\prime}}$ means the effect of $g$ on $w$, when $g^{\prime}$ is held constant.

Substituting equation 6.3 into equation 6.1 , for $z=g$, and neglecting changes in 'transmission', one obtains

$\Delta \bar{g}=\left[\beta_{w g . g^{\prime}} \operatorname{cov}(g, g)+\beta_{w g^{\prime} \cdot g} \operatorname{cov}\left(g^{\prime}, g\right)\right] / \bar{w}$

Hence the condition for an increase in the average breeding value of the trait of interest $(\Delta g>0)$ is: 


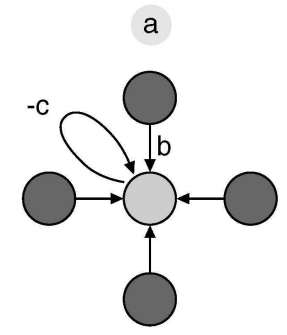

Neighbour-modulated fitness

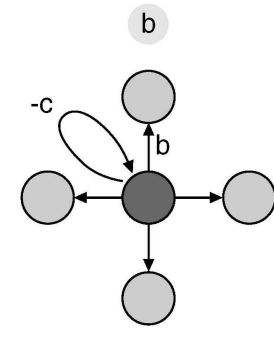

Inclusive fitness

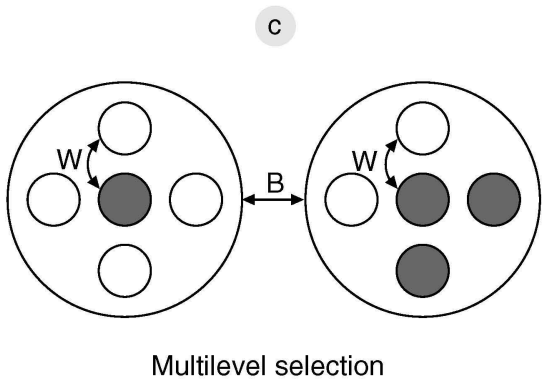

Multilevel selection

Figure 6.1 Three alternative but equivalent methods for solving the puzzle of altruism, via three different concepts. (a) Neighbourmodulated fitness: an average bearer of the altruistic genotype (lighter circle) will receive benefits (b, straight arrows) from other carriers of the altruistic genotype who express the trait in the individual's social neighbourhood (darker circles); if the individual itself expresses the altruistic genotype it will experience a direct fitness cost (-c, curved arrow). (b) Inclusive fitness: an individual that expresses the altruistic genotype (darker circle) will experience a direct fitness cost (-c, curved arrow) but cause fitness benefits to its social neighbours (b, straight arrows), some of whom may be more likely than chance to be carriers of the altruistic genotype. (c) Levels of selection: cooperators (open circles) experience a within-group disadvantage against cheats (filled circles), leading to a negative within-group selection component $\mathrm{W}$, but groups with more cooperators end up being more productive, leading to a positive between-group selection component $\mathrm{B}$.

$\beta_{w g \cdot g^{\prime}}+\beta_{w g^{\prime} \cdot g} \cdot \beta_{g^{\prime} g}>0$

This inequality is Hamilton's rule, $-c+b . r>0$, in its neighbour-modulated fitness form where $r=\beta_{g^{\prime} g}$ $=\operatorname{cov}\left(g^{\prime}, g\right) / \operatorname{cov}(g, g)$ is the coefficient of relatedness, which is defined as the least-squares regression of social-partner breeding value on one's own breeding value (Michod \& Hamilton 1980, Grafen 1985), $\beta_{w g . g^{\prime}}$ $=-c$ is the cost of carrying the genes for the social behaviour, and $\beta_{w g^{\prime} g}=b$ is the benefit one receives when one's social partners carry the genes for social behaviour.

From a neighbour-modulated fitness perspective, then, altruism can be favoured when $r>0$, or, more specifically, when the direct fitness cost $c$ to the actor is outweighed by the benefit $b . r$ of associating with neighbours who also carry genes for the social trait. The intuitive explanation is that with positive relatedness, altruistic individuals will tend to associate with other altruistic individuals that help them back. Meanwhile, non-altruistic individuals will associate with other non-altruists, and they will do badly. Relatedness $(r)$ measures the extent to which other individuals are more likely than chance to carry the same genes, and, as we have said, it is formally defined as a regression coefficient $\left(\beta g^{\prime} g\right)$. Nevertheless, regression relatedness is usually well approximated by genealogical relatedness under the assumption of weak selection, in which case it can be directly calculated from pedigrees (Michod \& Hamilton 1980, Grafen 1985). An exception where relatedness does not strictly correspond to genealogical relatedness, even for weak selection, is when it is caused by a phenotype-matching mechanism whereby cooperators directly recognise each other and preferentially interact (green-beard mechanisms: Hamilton 1964, Dawkins 1976, Traulsen \& Schuster 2003, Axelrod et al. 2004, Lehmann \& Keller 2006a, Gardner \& West 2010), or if the cooperator gene has a pleiotropic effect on habitat preference, so that individuals with cooperative genotypes would tend to assort together (Hamilton 1975). Nevertheless, both these mechanisms may be quite rare in nature (Lehmann \& Keller 2006a).

The neighbour-modulated-fitness approach to kin selection closely mirrors recent methodological developments in the theory of indirect genetic effects (IGEs, Chapter 2): both examine the consequences of genes carried by the focal individual and by the individual's social partners. However, kin-selection theory is typically concerned with between-individual genetic 
interactions at the fitness level only, and the phenotypic traits of key interest are usually assumed to be controlled by a single individual, whereas researchers working on IGEs are mostly motivated by phenotypic traits other than fitness, which are determined by genes carried by multiple individuals (Bijma \& Wade 2008).

Although Hamilton (1964) originally used individual genotypes as predictors of fitness, one could also express neighbour-modulated fitness as a function of an individual's and its social partner's phenotypes $y$ and $y^{\prime}$ (Frank 1998). This leads to the following phenotypic version of Hamilton's rule:

$\beta_{w y \cdot y^{\prime}}+\beta_{w y^{\prime} \cdot y} \cdot\left(\beta_{y^{\prime} g} / \beta_{y g}\right)>0$

in which costs and benefits are now defined as $\beta_{w y \cdot y^{\prime}}$ and $\beta_{w y^{\prime} \cdot y^{\prime}}$ and $r=\beta_{y^{\prime} g} / \beta_{y g}$ is interpreted as a measure of assortative interaction (Orlove \& Wood 1978) that measures the extent to which individuals carrying the altruistic genotype tend to interact with social partners with a cooperative phenotype (Eshel \& Cavalli-Sforza 1982, Nee 1989, Frank 1997a, Pepper 2000, Gardner \& West 2004, Fletcher \& Zwick 2006).

One problem, however, with using phenotypic fitness predictors is that this would change the way that social behaviours are classified (Table 6.1), and result in the erroneous classification of reciprocal altruism (Trivers 1971) as true altruism (Foster et al. 2006a, West et al. 2007b), which is defined as coming at a cost to the actor's lifetime fitness (Hamilton 1964). Consider, for example, a strategy whereby individuals only cooperate with others if they cooperated with them during a previous encounter (this is known as Tit-for-Tat in the literature: Axelrod \& Hamilton 1981). Here, there is a positive assortment between cooperators on a per-interaction basis, even if the interacting individuals are not genetic relatives (Nee 1989, Fletcher \& Zwick 2006). Assuming a large number of rounds of interaction, $\beta_{y^{\prime} g} / \beta_{y g}$ in this case turns out to be equal to $p$, the likelihood that two players meet again, leading to the condition that Tit-forTat is an evolutionary equilibrium when $p . b>c$ (Axelrod \& Hamilton 1981). Similarly, if individuals have information about the likely behaviour of social interactants, e.g. based on reputation (indirect reciprocity: Nowak \& Sigmund 1998), then $\beta_{y^{\prime} g} / \beta_{y g}$ measures the probability $q$ of knowing someone else's reputation (Suzuki \& Toquenaga 2005). Positive values of $\beta_{y^{\prime} g} / \beta_{y g}$ can even arise in interspecific interactions (Frank 1994a, Foster \& Wenseleers 2006), due to conditional (Tit-for-Tat-like) behaviour (Nee 1989, Fletcher \& Zwick 2006) or due to cooperative pairs gaining fitness benefits and staying together across multiple generations (Frank 1994a, Foster \& Wenseleers 2006).

Although some would find it pleasing that the relatedness coefficient $\beta_{y^{\prime} g} / \beta_{y g}$ in expression 6.6 brings out positive assortment as a key mechanism that can promote cooperation (Frank 1994a, Hamilton 1995, Skyrms 1996, Griffin \& West 2002, Fletcher \& Doebeli 2006), it has the disadvantage that it would misclassify behaviours that have delayed direct benefits as being truly altruistic. To avoid such confusion, we will use the genotypic version of Hamilton's rule (inequality 6.5) throughout the remainder of this chapter. That said, if phenotypes are not conditional on the social partner's behaviour and if phenotypes linearly map onto genotype (additive genetics: Chapter 1), then one does not need to make a distinction between expressions 6.5 and 6.6, as they will then be fully equivalent (McElreath \& Boyd 2007).

The regression-analysis form of Hamilton's rule outlined above has the benefit of allowing huge generality. The downside is that it can be awkward to analyse particular models in this way. Nevertheless, under the assumption that genetic variation is vanishingly small (i.e. if we are considering the spread of a rare mutant) and that mutants differ only slightly from the wild type (weak selection), one can switch from statistical, least-squares-regression analysis to methodology involving simpler expected-fitness functions that can be analysed using powerful calculus approaches (Box 6.1). This is because if there is vanishingly little genetic variation and variation in fitness, then the population occupies only a small segment of the function that relates genotype and phenotype, and hence the least-squares regressions of fitness on breeding value can be approximated by the tangent to the expected-fitness curve at the population-average breeding value, i.e. $\beta_{w g} \rightarrow$ $d w /\left.d g\right|_{g=\bar{g}}$, as $\operatorname{var}(g)$ and $\operatorname{var}(w) \rightarrow 0$. Making this transition from least-squares partial regressions to 
partial derivatives, expression 6.5 can be rewritten in differential-calculus form as

$$
\frac{\partial w}{\partial g}+\frac{\partial w}{\partial g^{\prime}} \frac{\mathrm{d} g^{\prime}}{\mathrm{d} g}>0
$$

where $\partial w / \partial g=-c$ is the cost of carrying genes for the social behaviour, $\partial w / \partial g^{\prime}=b$ is the benefit of one's social partners carrying genes for the social behaviour, and $\mathrm{d} g^{\prime} / \mathrm{d} g=r$ is the coefficient of genetic relatedness. This method forms the basis of a powerful maximisation approach to finding the evolutionarily stable strategy (ESS: Chapter 4) in social evolutionary models, which has truly revolutionised the field (Taylor \& Frank 1996, Taylor 1996, Frank 1997a, 1998, Taylor et al. 2007a; Box 6.1). As with the regression approach, extensions for classstructured populations are also readily made ( Taylor \& Frank 1996, Taylor et al. 2007a, Frank 1998; see section 6.3.1).

\section{The inclusive fitness approach}

The neighbour-modulated fitness approach focuses attention on a particular 'recipient' individual, and is concerned with how that individual's personal fitness is determined by the genes that it carries (direct fitness effects) and by the genes carried by its social partners (indirect fitness effects) (Fig. 6.1a). An alternative formulation, inclusive fitness, introduced by Hamilton (1964), instead focuses on how a random actor affects the fitness of others (Fig. 6.1b). Relatedness in this case measures the value of the recipient in transmitting copies of the actor's own genes, leading to an elegant gene-centered view of evolutionary change (Hamilton 1963, Dawkins 1976).

Formulating the selection of social traits in this way was a great breakthrough as it analyses gene frequency change entirely from the perspective of the actors that actually express the behaviour. In this way, it better captures the apparent agenda underlying organismal behaviour (Hamilton 1995, Grafen 2006, Gardner et al. 2007, Gardner \& Foster 2008, Gardner \& Grafen 2009). Organisms are expected to behave as if they value the reproductive success of their neighbours - devalued according to their genetic relatedness - as well as their own reproductive success. In short, they behave as if they are trying to maximise their inclusive fitness (Grafen 2006).

In our example, the inclusive fitness approach differs only from the neighbour-modulated fitness approach in the fact that the benefit term in Hamilton's rule is now calculated as the benefit to social partners $\left(\beta_{w^{\prime} g g^{\prime}}\right)$, rather than as the benefit of receiving help from social partners $\left(\beta_{\text {wg'.g }}\right)$ (Fig. 6.1a,b). Thus, the net inclusive fitness effect of an actor carrying a certain gene is calculated as

$\beta_{w g \cdot g^{\prime}}+\beta_{w^{\prime} g \cdot g^{\prime}} \cdot \beta_{g^{\prime} g}>0$

Because we assume no class structure, so that individuals are identical in all respects other than their genes for the social trait of interest (strategic equivalence: Grafen 2006), the impact of the focal individual's variant gene on the fitness of her social partner $\left(\beta_{w^{\prime} g g^{\prime}}\right)$ is equal to the impact on the focal individual's fitness that would occur if the social partner carried the variant gene $\left(\beta_{w g^{\prime} \cdot g}\right)$, and hence the conditions described by expressions 6.5 and 6.8 are equivalent. As in the neighbour-modulated fitness framework, the inclusive fitness effect is composed of two parts, a direct and indirect fitness effect, which are due to the effect of the actor's genotype on its own fitness and on the fitness of others, respectively (West et al. 2007a, 2007b). Whilst the direct fitness component retains the same meaning in both neighbour-modulated fitness and inclusive fitness approaches, the indirect fitness term describes the effect of social-partner genes on own fitness in the neighbour-modulated fitness view and the effect of own genes on social-partner fitness (weighted by relatedness) in the inclusive fitness view.

As before, when selection is weak and the population is nearly monomorphic, the partial regression coefficients in inequality 6.8 can be approximated using partial derivatives (see Box 6.1 for an example). In addition, as with the neighbour-modulated fitness approach to social evolution, the inclusive fitness approach can also be readily applied to class-structured populations (Taylor 1990, 1996; see section 6.3.1). 


\section{The levels-of-selection approach}

Price's (1970) theorem, which underpins the most general derivation of Hamilton's rule (Hamilton 1970), has also been applied to levels of selection in evolution (Price 1972, Hamilton 1975). Instead of separating individual fitness into direct and indirect components, this approach phrases social evolution in terms of selection within and between groups (Fig. 6.1c). Some researchers greatly prefer thinking in terms of this partition over the direct/indirect partition (Wilson 1975, 1983, Wade 1980, Sober \& Wilson 1998), and in recent years there has been much renewed interest in this theory (Keller 1999, Henrich 2004, Okasha 2006). Some of the earliest theoretical treatments of the evolution of altruism were also explicitly phrased in terms of opposing selection between and within groups (Wright 1945, Williams \& Williams 1957), and Darwin used both kinship and group-level arguments to explain social insect workers (Gardner \& Foster 2008). The combination of kin and group arguments used by Darwin reflects the fact that choosing a multilevel methodology over kin-selection thinking is just a question of how to phrase the problem. Sadly, however, there is a continuing tendency to mistakenly assume that switching between the methods also means that different biological processes are at play (e.g. Wilson 1975, Colwell 1981, Sober \& Wilson 1998, Gintis 2000a, Gintis et al. 2003, Fehr \& Fischbacher 2003, Wilson \& Hölldobler 2005, Nowak 2006, Traulsen \& Nowak 2006, Taylor \& Nowak 2007; see also Edward O. Wilson's profile). We feel this is misguided, given that the Price-equation derivations we use here show the compatability that allows results from one framework to be rephrased in terms of the other (see also Box 6.1).

Analysing social evolution in terms of opposing levels of selection is straightforward. Recall that the Price equation can be applied to describe selection among any type of entity. What we do first, then, is to take the standard form of the Price equation (equation 6.1) and use it to capture the effects of a change in the mean gene frequency on the mean fitness of individuals within a given group, rather than the effects of a change in individual genotype on absolute individual fitness as we did above. This requires a slight change in notation only, and we will now use subscripts $i$ and $i j$ to refer to the $i$ th group and the $j$ th individual within group $i$ respectively. Now we can write the evolutionary change in the average gene frequency $g$ as a function of the mean fitness and mean gene frequency in the $i$ th group as

$\bar{w} \Delta \bar{g}=\operatorname{cov}\left(w_{i}, g_{i}\right)+E_{i}\left(w_{i} \Delta g_{i}\right)$

Equation 6.9 describes selection on the groups in our population. But what about selection on individuals within each group? This is the clever part. Price (1972) noticed that one can expand the expectation term $E_{i}\left(w_{i} \Delta g_{i}\right)$ to capture the full effects of within-group selection because

$E_{i}\left(w_{i} \Delta g_{i}\right)=E_{i}\left(\operatorname{cov}_{i}\left(w_{i j}, g_{i j}\right)+E_{j . i}\left(w_{i j} \Delta g_{i j}\right)\right)$

where the right-hand side is a second version of the standard Price equation, but this time one level lower in the selective hierarchy, i.e. it describes within-group selection. Substituting this equation into equation 6.9 yields:

$$
\begin{aligned}
\bar{w} \Delta \bar{g}= & \operatorname{cov}\left(w_{i}, g_{i}\right)+E_{i}\left(\operatorname{cov}_{i}\left(w_{i j}, g_{i j}\right)\right. \\
& \left.+E_{j, i}\left(w_{i j} \Delta g_{i j}\right)\right)
\end{aligned}
$$

where the expectations and covariances are taken over their subscripts, with $i$ standing for groups, $i j$ standing for individual $j$ of group $i$, and $j . i$ for individuals $j$ for a specified group $i$. That is, the first covariance term captures the effects of the gene on group success, the second covariance term captures the effect of the gene on the relative success of individuals within a group, and the final term accounts for any deviations due to processes other than selection. This idea of expanding the Price equation to include multiple levels of selection can be continued until all relevant levels are included (e.g. the intragenomic level in the case of meiotic drive). Doing so, and disregarding mutation, the last term $\left(E_{j i}\left(w_{i j} \Delta g_{i j}\right)\right)$ can be set to zero. Noting that mean fitness $w$ is always greater than zero, it is then clear that a gene for a social trait is selected for when 
$\operatorname{cov}\left(w_{i}, g_{i}\right)+E_{i}\left(\operatorname{cov}_{i}\left(w_{i j}, g_{i j}\right)\right)=\beta_{w_{i} g_{i}} \cdot V_{g_{i}}+\beta_{w_{i j} g_{i j, i}} \cdot V_{g_{i j, i}}>0$

where, as we did above, the covariances have been broken up into their constituent regression and variance terms. In this inequality, the two sets of terms reflect between-group and within-group (amongindividual) selection respectively. Each level of selection entails a selective response equal to an intensity of selection (how the mean gene frequency at a certain level affects the relative fitness of that level) weighed by the genetic variance present at that level. The betweenand within-group genetic variances can be calculated using the techniques of classic population genetics, namely Wright's hierarchical F-statistics (Yang 1998). Importantly, however, they can also be expressed as a function of genetic relatedness, which links everything back to kin selection (Hamilton 1975, Breden 1990). To see this, one can multiply top and bottom of equation 6.12 by the total genetic variance in the population, yielding

$V_{t} \cdot\left(\beta_{w_{i} g_{i}} \cdot \frac{V_{g_{i}}}{V_{t}}+\beta_{w_{i j} g_{i j, i}}\right) \cdot \frac{V_{g_{i j, i}}}{V_{t}}>0$

where $V_{g_{i}} / V_{t}$ is known as Wright's intraclass correlation coefficient $R$ (Falconer 1981, Crow \& Aoki 1982; Box 6.1). Since $V_{t}=V_{g_{i}}+V_{g_{i j . i}}$ and is always positive, the inequality simplifies to

$\beta_{w_{i} g_{i}} \cdot R+\beta_{w_{i j} g_{i j, i}} .(1-R)>0$

where, for a group size of $n$, Wright's intraclass correlation coefficient $R$ equals $(1 / n)+((n-1) / n) . r$, with $r$ being the pair-wise genetic relatedness between group members (Hamilton 1975). As in the neighbour-modulated fitness and inclusive fitness approaches, when selection is weak and the population is nearly monomorphic, the partial regression coefficients in inequality 6.14 can be approximated using partial derivatives (see Box 6.1).

In group-selection models, positive between-group genetic variance often arises from limited migration (Crow \& Aoki 1982, Traulsen \& Nowak 2006). For example, under Wright's island-population model, it has been shown that the ratio of the within- to between-group genetic variance $(1-R) / R$ equals two times the number of migrant diploid organisms per generation (Wright 1951, Hamilton 1975, Crow \& Aoki 1982). This leads to the condition that if within-group and between-group selection terms are of equal magnitude $\left(\beta_{w_{i} g_{i}}=\beta_{w_{i j} g_{i j . i}}\right)$, between-group selection can override within-group selection only when less than one migrant is exchanged every two generations (Crow \& Aoki 1982, Leigh 1983). Taking a kin-selection approach, this would be interpreted as limited migration increasing relatedness and causing greater cooperation.

Expression 6.14 is very useful for conceptualising the potential tension between the within-group interests of individuals and the needs of the group as a whole (Hamilton 1975), and provides a formal foundation upon which to rest group-selection analyses. In particular, the among- and within-group genetic variances $R$ and $1-R$ determine the extent to which the group and the individual within the group can be considered units of selection (Wenseleers et al. 2003), and the signs of the $\beta$ coefficients tell us whether a trait either benefits or harms the group $\left(\beta_{w_{i} g_{i}}>0\right.$ or $<0$ ), and increases or decreases the fitness of individuals relative to other individuals within the same group $\left(\beta_{w_{i j} g_{i j . i}}>0\right.$ or $\left.<0\right)$. This allows for a classification of social behaviours similar to that in the inclusive fitness scheme (Table 6.1). The classification, however, is not completely identical, since even with zero relatedness, investment in an individually costly trait $\left(\beta_{w_{i j} g_{i j . i}}<0\right)$ could result in a net increase in absolute individual fitness when it results in a sufficiently large feedback benefit to the whole group (specifically, this occurs when $\left.\beta_{w_{i} g_{i}}>\beta_{w_{i j} g_{i j . i}} /(n-1)\right)$. Such traits are referred to as weakly altruistic, to differentiate them from true strong altruism, which entails direct fitness costs to individuals expressing the trait (Wilson 1990, Foster et al. 2006b).

Expression 6.14 clarifies that the kin selection and group selection approaches to social evolution are entirely interchangeable, and are not competing hypotheses about how social evolution occurs, as was often been claimed. Instead, group selection - as formalised by the multilevel Price equation - and the direct or inclusive fitness methods are simply alternative fitness accounting schemes that lead to the same 
net selective result (Hamilton 1975, Wade 1980, Crow \& Aoki 1982, Queller 1992a, Dugatkin \& Reeve 1994, Wenseleers et al. 2003, Lehmann et al. 2007a). To see this, take the example of altruism between a pair of interacting individuals, where the fitness of the two individuals is given by $w_{i 1}=\bar{w}-c \cdot\left(g_{i 1}-\bar{g}\right)+b \cdot\left(g_{i 2}-\bar{g}\right)$ and $w_{i 2}=\bar{w}-c \cdot\left(g_{i 2}-\bar{g}\right)+b \cdot\left(g_{i 1}-\bar{g}\right)$. The mean fitness of the pair $w_{i}=\bar{w}+(b-c) \cdot\left(g_{i}-\bar{g}\right)$, and since $g_{i}=\left(g_{i 1}\right.$ $\left.+g_{i 2}\right) / 2$, individual fitness can be written as $w_{i j}=\bar{w}-$ $c .\left(g_{i j}-\bar{g}\right)+b .\left(2 g_{i}-g_{i j}-\bar{g}\right)$. Nothing that $\beta_{w_{i} g_{i}}=\partial w_{i} /$ $\partial g_{i}=b-c, \beta_{w_{i j} g_{i j . i}}=\partial w_{i j} / \partial g_{i j}=-(b+c)$ and $R=(1+$ $r) / 2$, and substituting these terms into inequality 6.14 , shows that increased altruism is selected for when $(b-$ c) $(1+r) / 2-(b+c)(1-r) / 2>0$, which indeed just simplifies to Hamilton's rule, $b . r>c$ (Hamilton 1975, Wade 1980, Queller 1992a).

One drawback of the multilevel framework is that in principle, it applies only to strictly hierarchically nested populations, and usually requires that all individuals are equivalent and equally likely to express the trait under study. Hence it cannot easily deal with situations where the individuals affected by the altruistic behaviour belong to different sex or age classes. This is in contrast to kin selection theory, where the impact of class structure has been given a very general treatment. (Taylor 1990, Taylor \& Frank 1996, Taylor et al. 2007a; see section 6.3.1). A general theory of class structure for multilevel selection models is currently lacking. However, multilevel selection analysis of class structured models has been made possible by using the number of grand offspring as a proxy for fitness (Wilson \& Colwell 1981, Frank 1986), by including the genetic variance present in different classes of individuals affected by a social trait in the between-group genetic variance (Wenseleers et al. 2003) or even by using inclusive fitness theory to partition selection in components that owe to fitness differences between groups and between individuals within groups (Ratnieks \& Reeve 1992).

In addition, some have argued that the multilevel Price equation does not always properly capture people's intuitive notion of group selection. For example, it has been suggested that it is problematic that one could have between-group selection even in contexts not involving social traits (reviewed by Okasha 2006). For example, if good eyesight enhances individual fitness in a straightforward way, then some groups will be fitter than others simply because they contain, by chance, better-sighted individuals (Hamilton 1975). However, it is equally intuitive toidentify group selection as the part of natural selection that owes to fitness differences between groups, whether or not social behaviour is involved. Furthermore, it is Price's between-group selection that is identified as the driver of group-level adaptation in superorganism theory (Wilson \& Sober 1989, Gardner \& Grafen 2009), and this provides further justification for terming this part of natural selection "group selection".

An alternative approach aimed at remedying some of these perceived problems is 'contextual analysis' (Heisler \& Damuth 1987). This mirrors the neighbourmodulated fitness approach discussed above, and describes individual fitness as a function of its own genes or behaviour $\left(g_{i j}\right)$ and the mean gene frequency or behaviour $\left(g_{i}\right)$ or other characteristics of its group. Next, the selection for the social trait is decomposed as

$\beta_{w_{i j} g_{i j} \cdot g_{i}} \cdot \beta_{g_{i j} g_{i j}}+\beta_{w_{i j} g_{i} \cdot g_{i j}} \cdot \beta_{g_{i} g_{i j}}=\beta_{w_{j} g_{i j} \cdot g_{i}}+\beta_{w_{i j} g_{i} \cdot g_{i j}} \cdot R>0$

where $\beta_{w_{i j} g_{i} g_{i j}}$ is the impact of the group character on individual fitness, and is taken to be a measure of group selection, and $R$ is Wright's intraclass correlation coefficient $R=(1 / n)+((n-1) / n) \cdot r$, where $r$ is the pair-wise genetic relatedness between group members (Hamilton 1975). Although contextual analysis avoids the diagnosis of group selection in the hypothetical example of good eyesight, it has its own difficulties (Heisler \& Damuth 1987, Goodnight et al. 1992). For example, if we consider again the selection for individual eyesight, but now assume soft selection (Goodnight et al. 1992, Okasha 2006) is in operation so that every group is constrained to have the same total productivity, then an individual with particularly strong group mates would tend to have lower fitness than it would in another group. Contextual analysis would diagnose group selection in this scenario, because individual fitness depends on the group environment. However, the general consensus is that group selection should require fitness differences between groups, so there appears to be a mismatch between the formalism and 
the fundamental process that it was intended to capture (West et al. 2008). We emphasise that this is not necessarily a failing of the levels-of-selection or contextualanalysis approaches, but rather a failure to find a match between the theory and semantics of group selection.

On a final note, it should be mentioned that specieslevel selection is distinct from the multilevel theory outlined above, as it is not concerned with gene frequency change, but with rates of speciation or species extinction. For example, the evolution of asexuality in multicellular organisms appears to be associated with low species persistence times, i.e. multicellular asexuals are particularly prone to extinction and this makes them relatively rare in nature. Such processes do not directly affect the evolution of the trait itself as is the case for within- or between-group selection - but rather the frequency of the trait in the natural world. Despite this, species-level selection is still often referred to as a multilevel selection problem (Heisler \& Damuth 1987), and it can also be analysed using the
Price equation (equation 6.1) by taking $w_{j}$ as the rate with which a species $j$ speciates or tends to go extinct as a function of some characteristic $g_{j}$ (say geographic range) (Arnold \& Fristrup 1982, Okasha 2006). In this case, the covariance would measure species-level selection, and the expectation the fidelity of transmission of the trait to daughter species (Arnold \& Fristrup 1982, Okasha 2006). Interestingly, it has recently been shown that species-level selection can potentially reduce the mean level of selfishness observed among species. As with asexuals, there is some evidence that more selfish species are more prone to extinction than more cooperative species (Parvinen 2005, Rankin \& López-Sepulcre 2005, Rankin 2007, Rankin et al. 2007). The prediction then is that while natural selection may frequently favour the evolution of selfish strategies within a species, species-level selection may counter this. If correct, this will mean that cooperative species are more common in nature than would be predicted by within-species processes alone.

Box 6.1 The different ways of analysing social evolution

To illustrate the different methods, we here analyse Frank's (1994b, 1995b) 'tragedy of the commons' model, which has been successfully applied to a variety of biological problems (Frank 1994b, Foster 2004, Wenseleers et al. 2003, 2004a, 2004b). The tragedy of the commons states that each individual would gain by claiming a greater share of the local resources, but that the group would perish if all local resources were exhausted (Hardin 1968). Frank's model captures this tension between group and individual interests by writing individual fitness as

$w_{i j}=\left(1-g_{i}\right) \cdot\left(g_{i j} / g_{i}\right)$

where $g_{i j}$ and $g_{i}$ are the individual and group mean breeding values for a behaviour that causes individuals to selfishly grab local resources (normalised to go from 0 to 1 ). In this simple model, $1-g_{i}$ is the group's productivity, which declines as the average level of selfishness $g_{i}$ increases (we assume linearly, but this can easily be relaxed: Foster 2004) and $g_{i j} / g_{i}$ is the relative success of an individual within its group. Similarly, we can write the fitness of another member in the group as

$w^{\prime}=\left(1-g_{i}\right) \cdot\left(g^{\prime} / g_{i}\right)$

where $g^{\prime}$ is the average level of selfishness of these other individuals. Note that with a group size of $\left.\left.n, g_{i}=(1 / n) g_{i j}+((n-1) / n) g^{\prime}\right)\right)$, which we can substitute into equations 6.B1 and 6.B2.

From a neighbour-modulated fitness perspective, a rare mutant that is slightly more selfish than the wild type is favoured when 
$\partial w_{i j} / \partial g_{i j}+\partial w_{i j} / \partial g^{\prime} \cdot r>0$

because an individual carrying the mutation would experience a direct cost $\partial w_{i j} / \partial g_{i j}$ but with probability $r$ would be paired with group mates that also carry the mutation, hence resulting in a return benefit of $\partial w_{i j} / \partial g^{\prime}$.

Similarly, from an inclusive fitness perspective, a rare, slightly more selfish mutant is favoured when

$\partial w_{i j} / \partial g_{i j}+(n-1) . \partial w^{\prime} / \partial g_{i j} \cdot r>0$

because an individual actor that expresses the mutant behaviour would experience a direct cost $\partial w_{i j} / \partial g_{i j}$ but impose a cost of $\partial w^{\prime} / \partial g$ to each of its $n-1$ group mates, which with probability $r$ would carry copies of its own mutant gene. It is easily checked that since $\partial w^{\prime} / \partial g=\left(\partial w / \partial g^{\prime}\right)\left(g^{\prime} / g_{i j}\right) /(n-1)$, and since mutations have small effect so that $g^{\prime} \cong g_{i j^{\prime}}(n-1) . \partial w^{\prime} / \partial g_{i j}=\partial w_{i j} / \partial g^{\prime}$, and inequalities 6.B3 and 6.B4 are therefore equivalent.

Finally, from a levels-of-selection perspective, selection would be partitioned into components that are due to the differential fitness of groups with different mean levels of selfishness and the differential success of more versus less selfish individuals within groups. Specifically, if we call $G$ group productivity and $I$ individual fitness relative to other group members, we have $G=w_{i}=\left(1-g_{i}\right), I=w_{i j} / w_{i}=g_{i j} / g_{i}$ and individual fitness $w_{i j}$ $=$ G.I. From equation 6.12 it is clear that a more selfish mutant will be selected for when positive within-group selection balances with negative among-group selection:

$\partial w_{i j} / \partial g_{i j} \cdot(1-R)>-\partial w_{i} / \partial g_{i} \cdot R$

where $R$ and $1-R$ are proportional to the between- and within-group genetic variances and $R=(1 / n)+((n-1) / n) \cdot r$ is known as Wright's intraclass correlation coefficient. Note that the among- and within-group selection components are also sometimes calculated in an equivalent way as $\partial w_{i j} / \partial G . d G / d g_{i j}=I . \partial G / \partial g_{i} \cdot d g_{i} / d g_{i j}=I . \partial G / \partial g_{i} \cdot R$ and $\partial w_{i j} / \partial I . d I / d g_{i j}=G .\left(\partial I / \partial g_{i j} \cdot d g_{i j} / d g_{i j}+\partial I / \partial g_{i} \cdot d g_{i} / d g_{i j}\right)=G .\left(\partial I / \partial g_{i j}+\partial I / \partial g_{i} \cdot R\right)$ (cf. Ratnieks \& Reeve 1992), which has the advantage that these only require the calculation of derivatives, and do not involve variances.

Differently still, using contextual analysis (inequality 6.15), we can see that a more selfish mutant can invade when

$\beta_{w_{i j} g_{i j} \cdot g_{i}}+\beta_{w_{i j} g_{i} \cdot g_{i j}} \cdot R>0$

Reassuringly, the evaluation of the partial derivatives in equations 6.B3 to $6 . \mathrm{B} 6$ for the case where $g_{i j} \cong g^{\prime} \cong g_{i} \cong g$ shows that, no matter how we partition social evolution, the net selective effect is the same, and that an equilibrium is reached when $g^{*}=1-R$, i.e. the equilibrium level of selfishness decreases as relatedness, or more specifically, the intraclass correlation coefficient, increases. At this equilibrium, no mutant that behaves slightly differently can invade in the population (Maynard Smith 1982). In addition, it can be checked that the equilibrium is evolutionarily stable, i.e. a fitness maximum, since the derivatives of the above fitness gradients $D$ (equations 6.B3-6.B6) with respect to $g_{i j}$ are negative. Finally, an additional stability criterion, convergence stability, specifies whether the equilibrium is an attractor or not, and is therefore attainable, and requires that the fitness gradient is positive when evaluated for $g$ slightly below $g^{*}$ and 


\begin{abstract}
Box 6.1 Continued
negative when $g$ is slightly higher than $g^{*}$. Formally, this occurs when $\partial D /\left.\partial g^{*}\right|_{g_{i j}=g^{\prime}=g_{i}=}$ $\mathrm{g}^{*}<0$ (Eshel \& Motro 1981, Taylor 1996). A strategy that is simultaneously evolutionarily and convergence stable is termed a continuously stable strategy (CSS: Eshel 1983, Christiansen 1991), and it can be checked that the equilibrium in our example is indeed a CSS. Strategies that are convergence stable but not evolutionarily stable, however, are also possible, and can lead to disruptive selection and evolutionary branching (Metz et al. 1992, Geritz et al. 1998). Evolutionary branching points are interesting, as they provide us with the conditions under which continuous or mixed-strategy ESSs would be expected to evolve towards discrete-strategy ESSs (see section 6.3.1 and Doebeli et al. 2004 for an example).
\end{abstract}

\subsubsection{Which method is best?}

As we have demonstrated, for a wide variety of problems it is possible to analyse social evolution in an equivalent way based on the concepts of neighbour-modulated fitness, inclusive fitness or multilevel selection (Fig. 6.1, Box 6.1). These methods are simply different fitness accounting schemes, which in all cases lead to the same net gene frequency change. Neighbourmodulated fitness is perhaps closest to how natural selection actually works, and analyses social evolution in terms of correlated interaction, whereby individuals carrying a gene for a social trait would tend to interact more $(r>0)$ or less $(r<0)$ likely than chance with other individuals expressing the social trait. In recent years, neighbour-modulated fitness has emerged as one of the most popular methods for modelling kin selection (e.g. Frank 1998, Gandon 1999, Day 2001, Leturque \& Rousset 2003, Wild \& Taylor 2005, Pen 2006). Inclusive fitness instead adds up the effects of the actor's social behaviour on all recipients, using relatedness as the value of each recipient in helping to propagate copies of the actor's own genes. Inclusive fitness, in tracking the various fitness effects of a single individual's behaviour, mirrors the way that most evolutionary biologists think, particularly within the discipline of animal behaviour, and, likely for that reason, remains the preferred mode of analysis for most biologists. Finally, a levels-of-selection perspective takes explicit account of the hierarchical nature of biological systems, and analyses social evolution in terms of opposing selection within and among groups. This tells us to what extent evolution will favour maximal group success, or maximal individual success, relative to other group members (Sober \& Wilson 1998). The contextual-analysis approach makes a similar partition of individual and group effects that can be useful for understanding the causal mechanisms of social evolution.

Which of these methods is preferable is partly a matter of taste, as each of them offers certain advantages, and may be more intuitive for any particular problem (Queller 1992a, Dugatkin \& Reeve 1994, Foster 2006). In addition, all of these frameworks have led to unique, original insights (West et al. 2007b, 2008, Wilson \& Wilson 2007, Wilson 2008). On the other hand, at a technical level, it is fair to say that the kin-selection approach (neighbour-modulated and inclusive fitness methods) has been developed to a much greater extent than the group-selection approaches (levels of selection and contextual analysis), and is the only method that can easily take into account class structure (Frank 1998, Rousset 2004, West et al. 2008; also section 6.3.1 and Chapter 12, but see Frank 1986, Ratnieks \& Reeve 1992, Wenseleers et al. 2003). Furthermore there is some controversy over whether or not the levels-of-selection and contextual analysis approaches succeed in capturing the process of group selection for which they were originally devised (Okasha 2006, Wilson \& Wilson 2007, West et al. 2008). Finally, Gardner \& Grafen (2009) have argued that only inclusive fitness theory provides a clear adaptationist interpretation of the action of natural selection, with the dynamics of gene frequency 
change formally corresponding to the design objective of inclusive-fitness maximization (Grafen 2006). In contrast, there is no formal justification for regarding groups as fitness-maximizing agents, unless within-group selection can be considered negligible (Gardner \& Grafen 2009). As a corollary, however, one could say that levels of selection theory also provides a maximand of selection, but one which within that framework would be a weighted average of group and relative, individual success. This suggestion, however, still remains to be formalized.

Whatever one's opinion of the different methodologies, it is clear that all have led to important and interesting insights. The prominence of genetic relatedness in kin-selection models has led to numerous tests that confirm its importance. These include considerable evidence from the social insects that patterns of kin structure within colonies are central to the balance between cooperation and conflict (Wenseleers \& Ratnieks 2006b, Ratnieks et al. 2006, Ratnieks \& Wenseleers 2008; Box 6.2, Fig. 6.2), data from social vertebrates that relatedness is linked to helping behaviour (Griffin \& West 2003) and a growing body of evidence that genetic relatedness is important in microbial groups (Chapter 13). Meanwhile, consideration of the potential for group selection has led to a series of experiments that show the differential productivity of groups, and even communities, can strongly affect evolutionary trajectories (Chapter 2; Wade 1976, 1977, Wilson 1997, Wade \& Goodnight 1998, Swenson et al. 2000, Bijma \& Wade 2008). Group selection logic has also had practical applications (Bijma \& Wade 2008): selecting chickens (Gallus gallus domesticus) for productivity at the level of groups in cages increases yield more than selecting for individual egg-laying ability (Muir 1996, 2005, Craig \& Muir 1996).

\subsection{Complexities in modelling social evolution}

In the sections above we introduced the general approaches by which social evolution can be modelled, and illustrated these using a few very simple examples. In practice, however, several complications may arise. While it is not our intention to show how all of these can be dealt with, we will provide some key pointers to the relevant literature.

\subsubsection{Multiple classes of individuals}

The most common complication is that a social trait affects not just the individual's own age or sex class, but also that of one or more other classes of individuals, which usually do not themselves express the trait. The problem, then, is to correctly calculate the average fitness consequences of carrying the gene for such a trait across all classes (in a neighbour-modulated fitness scheme), or, from an actor's point of view, to correctly value a member of each class of recipients in mediating gene frequency change (in an inclusive fitness scheme). For example, it is clear that a sexually mature individual should be valued differently than an aged individual that is about to die.

One can account for the differences in value among classes in a neighbour-modulated fitness model using something appropriately called the class reproductive value $c_{k}$ (Taylor 1990, Taylor \& Frank 1996, Taylor et al. 2007a), which is the product of the number of individuals $u_{k}$ in a given class $k$ and each of its members' reproductive value $v_{k^{\prime}}$ which measures the ability of an individual of class $k$ to contribute to the future gene pool (Fisher 1930). Another way to think about $c_{k}$ is to recall that in a neighbour-modulated fitness model, one must determine the average effect of a gene coding for a social trait in a random carrier, such that picking a random carrier would mean picking an individual of a certain class with relative probability $c_{k}$ (Taylor 1990, Taylor \& Frank 1996, Taylor et al. 2007a). More technically, if we write the transmission probabilities between the different classes of individuals in a stable population (i.e. in the absence of selection) as a matrix $A$, then $c=v \cdot u$, and $u$ and $v$ are the dominant right and dominant left eigenvectors of $A$ (Taylor \& Frank 1996). For an age-structured population, $A$ is known as the Leslie matrix (Bulmer 1994).

To give an example, Wenseleers et al. (2003) discussed the case of stingless bees of the genus Melipona where female larvae can control their own caste development and gain a fitness advantage by increasing their probability of developing into queens rather 

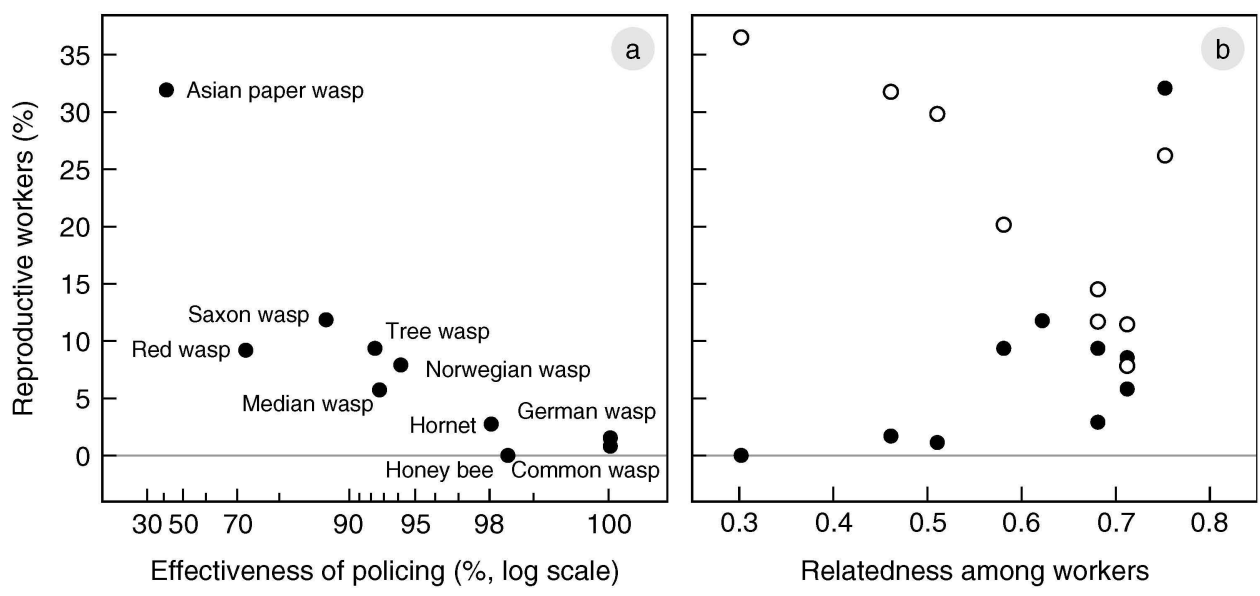

Figure 6.2 Testing social evolution theory: the effect of policing efficiency and relatedness on male production by workers in the eusocial Hymenoptera (see Box 6.2). (a) A comparative analysis of nine wasp species and the honey bee Apis mellifera shows that significantly fewer workers attempt to reproduce when the eggs they lay are more effectively killed or 'policed' by nestmates. (b) The effect of worker relatedness on worker male production. Here one must distinguish between colonies with a queen and those without a queen. In colonies with a queen, worker policing occurs, and this is what drives the frequency of laying workers. Moreover, and for reasons we have not discussed (see Ratnieks \& Wenseleers 2008 for a review), the strength of policing correlates negatively with relatedness. This means that, somewhat paradoxically, more workers reproduce in species with a queen (filled circles) when workers are more related to each other. In queenless colonies (open circles), however, the relationship is reversed and, as predicted by Hamilton's rule, workers are more altruistic and fewer lay eggs in the species where they are more related to each other. Data from Wenseleers and Ratnieks (2006b).

than workers. Colony productivity, however, would go down as more larvae chose to develop into queens, due to the resultant shortage of workers, and this would reduce both male production and the production of new daughter swarms. Similar to Frank's tragedy of the commons model (Box 6.1), this situation was captured by assuming that male production is given by $W_{m}=$ $1-g_{i}$ and that the relative success of a female larva (the relative probability that she heads the swarm, multiplied by the likelihood of it being produced) is given by $W_{f}=\left(g_{i j} / g_{i}\right)\left(1-g_{i}\right)$, where $g_{i j}$ and $g_{i}$ are the individual and colony average probabilities with which larvae turn into queens, and with $\left.\left.g_{i}=(1 / n) g_{i j}+((n-1) / n) g_{i j}{ }^{\prime}\right)\right)$, where $n$ are the number of competing female larvae and $g_{i j}{ }^{\prime}$ is the average genetic value of the social partners of the focal individual $i j$. Following a neighbourmodulated fitness logic, a mutant that makes larvae develop into queens with a slightly higher probability is favoured when $c_{f}\left(\partial W_{f} / \partial g_{i j}+\partial W_{f} / \partial g^{\prime} \cdot r_{f}\right)+c_{m} \cdot \partial W_{m} / \partial g_{i}$ $r_{m}>0$, where $c_{f}$ and $c_{m}$ are the class reproductive values of queens and males, and $r_{f}$ and $r_{m}$ are the regression relatedness values of larvae to sisters and males reared in the colony. From this, it is readily shown that when $n$ is large, the ESS is for larvae to develop into queens with a probability of $\left(1-r_{f}\right) /\left(1+\left(c_{m} / c_{f}\right) \cdot r_{m}\right)$. For the case where colonies are headed by a single once-mated queen and where all males are produced by the queen, this results in an ESS in which $20 \%$ of the females should develop into queens, since due to haplodiploidy $c_{m} / c_{f}$ $=1 / 2, r_{f}=3 / 4$ and $r_{m}=1 / 2$ (Hamilton 1972, Bourke \& Franks 1995), a result that in fact is quite close to empirically observed ratios (Wenseleers \& Ratnieks 2004).

This same result can be recovered from an inclusive fitness analysis, illustrating the equivalence of approaches. The inclusive fitness effect of an increase in queen development probability of a focal female larva is given by $\partial W_{f} / \partial g_{i j} v_{f}+(n-1) . \partial W_{f}^{\prime} / \partial g_{i j} v_{f} r_{f}+m . \partial W_{m}^{\prime} / \partial g_{i j} v_{m} . r_{m^{\prime}}$ where $W_{f}^{\prime}=\left(1-g_{i}\right)\left(g_{i j}^{\prime} / g_{i}\right)$ is the fitness of another female 
larva in the colony, $W_{m}{ }_{m}=\left(1-g_{i}\right)$ is the fitness of a male in the colony, $m$ are the number of males produced over a colony's lifetime, $v_{f}$ and $v_{m}$ are the individual reproductive value of female larvae and males, and $r_{f}$ and $r_{m}$ are the regression relatedness to them, respectively. Simplifying by dividing everything by $v_{f}$ yields $\partial W_{f} / \partial g_{i j}$ $+(n-1) . \partial W_{f}^{\prime} / \partial g_{i j} R_{f}+m . \partial W_{m}^{\prime} / \partial g_{i j} R_{m}$, where $R_{f}=r_{f}$ and $R_{m}=r_{m} \cdot\left(v_{m} / v_{f}\right)$ are the life-for-life relatedness to females and males, which are defined as the product of regression relatedness and relative reproductive value (Hamilton 1972, Taylor \& Frank 1996, Taylor et al. 2007a). Observing that $\left(v_{m} / v_{f}\right)=\left(c_{m} / c_{f}\right) \cdot\left(u_{f} / u_{m}\right)=\left(c_{m} / c_{f}\right) \cdot(n / m)$ and setting the inclusive fitness effect to zero and solving for $g_{i j}=g_{i j}^{\prime}=$ $g_{i}=g=g^{*}$ obtains the ESS $g^{*}=\left(1-r_{f}\right) /\left(1+\left(c_{m} / c_{f}\right) \cdot r_{m}\right)$.

Other examples of class-structured kin selection models involving interactions between different age classes are discussed by Charlesworth and Charnov (1981), Taylor and Frank (1996) and Taylor et al. (2007a).

Box 6.2 A model and an empirical test: worker male production in the social insects

In order to illustrate the predictive power of social evolution theory, we here describe a model and associated data for a classic problem in sociobiology: the evolution of worker sterility. Specifically, we are focusing on the evolution of male production by workers. The eusocial Hymenoptera (bees, wasps and ants) are haplodiploid: males are haploid and females are diploid. This means that unmated workers in many species are able to lay unfertilised, haploid eggs that would develop into males if reared. Nevertheless, despite this ability workers in many species appear to refrain from laying eggs. Why is this so?

Wenseleers et al. (2004a, 2004b) analysed this problem using an inclusive fitness model. Specifically, they asked what are the factors that determine the frequency of workers that attempt to lay eggs in insect societies. We review the model here because its specific predictions have subsequently been shown to hold in real systems. Let $n$ be the number of workers in the colony, $p$ the probability that a worker-laid male egg is removed by another individual (the queen and workers remove or 'police' workerlaid eggs in many species: Wenseleers \& Ratnieks 2006a), and $q$ the fecundity of the queen relative to a single reproductive worker in terms of laying male eggs. Assume that a focal worker $j$ in colony $i$ activates her ovaries to lay eggs with probability $g_{i,}$, and that each of its $n-1$ nestmates activates her ovaries with probability $g_{i j}^{\prime}$, so that the colony contains $n g_{i}$ egg-laying workers where $g_{i}$ is the average probability with which workers activate their ovaries, $g_{i}=(1 / n) g_{i j}+((n-1) / n) g_{i j}^{\prime}$. We can now write the total number of males produced by this focal worker and by each nestmate worker as $W_{m w}=$ $G\left(g_{i}\right) \cdot g_{i j}(1-p) /\left(n g_{i}(1-p)+q\right)$ and $W^{\prime}{ }_{m w}=G\left(g_{i}\right) \cdot g_{i j}^{\prime}(1-p) /\left(n g_{i}(1-p)+q\right)$, where $G\left(g_{i}\right)$ is the colony productivity (total number of males reared) as a function of how many laying workers there are in the colony (egg-laying workers generally perform less work and so decrease total colony productivity) and the terms following $G$ represent the proportion of all males that are workers' sons. That is, the total number of sons of the focal and other workers that survive policing, divided by all surviving males, which includes both workers' sons $\left(\left(n g_{i}(1-p)\right)\right.$ and queen's sons, laid in proportion to the relative rate $q$ at which these are produced. For simplicity, we will assume that worker reproduction linearly reduces colony productivity, i.e. $G=1-g_{i}$, because fewer workers will work when more reproduce.

By a similar argument, the total number of males produced by the queen is $W_{m q}=$ $G\left(g_{i}\right) \cdot q /\left(n g_{i}(1-p)+q\right)$. 


\section{Box 6.2 Continued}

Finally, the total amount of female reproduction by the colony (winged queens, or swarms for swarm-founding species such as honey bees Apis mellifera) is also a decreasing function of $g_{i}$. For simplicity, we assume that worker reproduction reduces queen and male production equally. Hence, the total number of queens or swarms produced is $W_{f}=G\left(g_{i}\right)=1-g_{i}$.

The inclusive fitness effect of increasing the probability of becoming a laying worker for a focal individual is given by $\partial W_{m w} / \partial g_{i j} v_{m} \cdot r_{\text {son }}+(n-1) \cdot\left(\partial W_{m w}^{\prime} / \partial g_{i j}\right) \cdot v_{m} \cdot r_{n e p h e w}+$ $\left(\partial W_{m q} / \partial g_{i j}\right) \cdot v_{m} \cdot r_{\text {brother }}+\left(\partial W_{f} / \partial g_{i j}\right) \cdot v_{f} r_{\text {sister }}$

Finally, in haplodiploids, one must make adjustments for the fact that males only carry half the genes of females, i.e. males will often have a lower reproductive value than females (reviewed in Bourke \& Franks 1995). This gives so-called 'life-for-life relatedness coefficients' of $R_{\text {son }}=r_{\text {son }} \cdot v_{m}=1 . v_{m^{\prime}}, R_{\text {nephew }}=r_{\text {sister }} v_{m}$ and $R_{\text {brother }}=r_{\text {brother }}$ $v_{m}=(1 / 2) \cdot v_{m}$, where $v_{m}$ is the relative reproductive value of males to females, which is $1 / 2(2-\psi)$ where $\psi$ is the population-wide proportion of males that are workers' sons (Pamilo 1991). In our case, it can be seen that $\psi=n g(1-p) /(n g S+q)$, where $g$ is the average proportion of laying workers in an average colony in the population. Setting the inclusive fitness effect to zero and solving for $g_{i j}=g_{i j}^{\prime}=g_{i}=g=g^{*}$ obtains the ESS:

$$
\begin{aligned}
& g^{*}=\frac{-B+\sqrt{B^{2}-4 A C}}{2 A} \\
& \text { with } A=2 n^{2}(1-p)^{2}\left(1+r_{\text {sister }}\right) \\
& B=2(1-p)\left(q\left(1+n-r_{\text {sister }}+4 n r_{\text {sister }}\right)+(n-1) n\left(1-r_{\text {sister }}\right)(1-p)\right) \\
& C=q\left(q\left(1+4 r_{\text {sister }}\right)-n(1-p)\right)
\end{aligned}
$$

The solution makes a number of predictions (Wenseleers et al. 2004a, 2004b) but here we will focus on two main insights. Firstly, species with the strongest policing, in which the queen or other workers efficiently remove worker eggs, should have the lowest proportion of laying workers. Intuitively, this is because the benefit to a worker of laying $\left(\partial W_{m w} / \partial g_{i j}\right)$ declines when fewer of her eggs are reared. Second, in the absence of egg removal by policing, the proportion of laying workers should decrease with increased relatedness among workers, because high sister-sister relatedness decreases the relatedness gain of replacing nephews with sons (Bourke 1988). Empirical data from wasps and bees have been shown to support both of these predictions (Wenseleers \& Ratnieks 2006b; Fig. 6.2).

\subsubsection{Non-additive fitness interactions and frequency-dependent selection}

In many situations the fitness consequences of the cooperative behaviour of actors and recipients do not simply add up (Queller 1984, 1985, 1992b). For example, consider a scenario where individuals interact in pairs in which each social partner chooses whether to cooperate or defect, and with cooperation carrying a personal $\operatorname{cost} C$ to the actor, giving a benefit
$B$ to the recipient, and additionally giving an extra benefit $D$ if the other individual also cooperates, in addition to a baseline fitness of 1 . The quantity $D$ has been described as the 'synergy' effect, and might be positive (benefit) or negative (cost) (Queller 1984, 1985).

If the cooperation phenotype is controlled in a probabilistic way, and a focal individual's genes encode a strategy value $g$ such that the individual cooperates 
with probability $g$ and defects with probability $1-g$, then we can express fitness as

$w=1-C \cdot g+B \cdot g^{\prime}+D \cdot g \cdot g^{\prime}$

where $g^{\prime}$ is the social partner's breeding value for the cooperation trait. If we make the assumption that $g$ is a quantitative character with vanishing variation around the population average of $\bar{g}$, then we can employ the usual derivation approach to determine the costs and benefits of cooperation in Hamilton's rule (Box 6.1; Taylor \& Frank 1996, Frank 1998), yielding the result that an increase in the level of cooperation will be selected for when

$\frac{\partial w}{\partial g}+\frac{\partial w}{\partial g^{\prime}} \cdot r=(-C+D \cdot \bar{g})+(B+D \cdot \bar{g}) \cdot r>0$

This identifies an equilibrium point at $g^{*}=(C-B r) /$ $(D(1+r))$ which, when it takes an intermediate value (between 0 and 1) is unstable for $D>0$ and stable for $D<0$ (Grafen 1979, Queller 1984, Wenseleers 2006). Note that while the cooperation and defection phenotypes have selective value that is frequency-dependent, the minor genetic variants that alter the probabilistic expression of these phenotypes are governed by selection that is frequency-independent.

Alternatively, the cooperation phenotype of an individual might be fully determined by its genotype, with some individuals carrying a cooperation allele $(g=1)$ and others carrying a defection allele ( $g=0$; for simplicity, we assume haploidy). In this case, the assumptions underlying the differentiation approach fail, and so we use the more general version of Hamilton's rule instead (inequality 6.5), $\beta_{w g \cdot g^{\prime}}+\beta_{w g^{\prime} \cdot g^{\prime}} \cdot \beta_{g^{\prime} g}>0$, where the costs and benefits of cooperation are defined as the partial

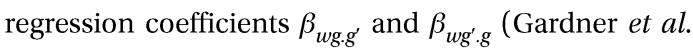
2007). These coefficients are defined so that fitness is predicted as a linear function of one's own and one's social partner's breeding value:

$\hat{w}=\bar{w}+\beta_{w g \cdot g^{\prime}}(g-\bar{g})+\beta_{w g^{\prime} \cdot g}\left(g^{\prime}-\bar{g}\right)$

and where mean fitness $w=f_{10} w_{10}+f_{11} w_{11}+f_{01} w_{01}$ $+f_{00} w_{00}, f_{X Y}$ is the frequency of $X Y$ pairs in the population, and $w_{X Y}$ is the fitness of an individual playing strategy $X$ against an individual playing strategy $Y$. The proportion of fitness variance that is not explained by the linear model is given by the average squared residual $S=\sum_{X, Y} f_{X Y}\left(w_{X Y}-\left.\hat{w}\right|_{g=X, g^{\prime}=Y}\right)^{2}$. We obtain the partial regression coefficients by the usual method of least squares, i.e. the values of $\beta_{w g . g^{\prime}}$ and $\beta_{w g^{\prime} g}$ that minimise $S$ and for which $\partial S / \partial \beta_{w g \cdot g^{\prime}}=\partial S / \partial \beta_{w g^{\prime} g}=0$, and Gardner et al. (2007) show that these are equal to

$\beta_{w g \cdot g^{\prime}}=-c=-C+\frac{r+(1-r) \bar{g}}{1+r} D$

$\beta_{w g^{\prime} \cdot g}=b=B+\frac{r+(1-r) \bar{g}}{1+r} D$

Hence in this case cooperation spreads when $-c+b . r$ $=-C+B \cdot r+D \cdot(r+(1-r) \bar{g})>0$, a condition that can be verified using a standard population-genetic approach (Grafen 1979, Queller 1984). The three parts in this equation split up additive and non-additive effects on fitness. Increasing one's level of cooperation incurs a cost $-C$ but also results in a benefit B. $r$ as a result of the cooperation received from neighbours. In addition, increasing one's level of cooperation will incur an extra non-additive benefit $D$ insofar as one's partner is also a cooperator, which will be the case in a proportion $(r+$ $(1-r) \bar{g}$ ) of all interactions. This third effect is due to the combined action of own and social-partner genes, the former being of relative importance 1 (the association between own genes and own phenotype) and the latter being of relative importance $r$ (the association between own genes and partner's phenotype), and so a proportion $1 /(1+r)$ of the effect is attributed to own genes and a proportion $r /(1+r)$ is attributed to partner's genes. Hence the direct fitness effect is $-c=-C+(1 /(1+r)) \cdot(r$ $+(1-r) \bar{g}) \cdot D$, and the indirect fitness effect is $b \cdot r=B \cdot r+$ $(r /(1+r)) \cdot(r+(1-r) \bar{g}) \cdot D$. Thus, in contrast to what has sometimes been claimed (Queller 1984, Bulmer 1994, Wenseleers 2006), Hamilton's rule $-c+b . r>0$ does hold for situations where strategies are discrete and selection is strong (major as opposed to minor genetic variants), provided that the fitness effects $b$ and $c$ are calculated according to their proper least-square-regression definitions (Gardner et al. 2007).

In contrast to typical models of kin selection, which assume that selection is weak and hence frequencyindependent (Hamilton 1995, Rousset 2004, 2006, 
Ross-Gillespie etal.2007), allowing for discrete strategies and strong selection generates frequency-dependent kin selection. In the above example, selection acting upon the cooperation gene $(g=1)$ depends on the frequency of this gene in the population $(\bar{g})$. If the synergy term $D$ is positive, then selection is positively frequency-dependent: either cooperation or defection or both cooperation and defection are evolutionarily stable, depending on parameter values, and there is no stable polymorphism between the two alleles. However, if the synergy term $D$ is negative, then selection is negatively frequency-dependent, and depending on parameter values the population will evolve either towards complete cooperation, complete defection, or a stable polymorphism between the two whereby cooperation is maintained at intermediate frequency $g^{*}=(C-(B+$ $D) r) /(D(1-r)$ ) (Grafen 1979, Queller 1984, Wenseleers 2006).

In principle, the same approach as outlined above could be used to deal with frequency dependence in an inclusive fitness or a levels-of-selection framework (Breden 1990). Nevertheless, it is fair to say that more work remains to be done on frequency dependence in social evolution models (see Grafen 2006, 2007a and commentaries on Lehmann \& Keller 2006a). This is perhaps surprising, given that in economics, game theory (Chapter 4) is almost entirely concerned with frequency-dependent interaction, even though, in contrast to kin-selection models, interactions are usually assumed to occur among non-relatives (Gintis 2000b).

\subsubsection{Multilocus models and non-additive gene action}

Both kin selection (equations 6.4 and 6.6) and multilevel selection (equation 6.11) have often been formulated so that the fitness predictors $g$ refer to the frequency of an allele in individuals at a single locus (Hamilton 1964, Wade 1980). This has led many to conclude that these methods are unrealistic, for clearly a social trait would unlikely be controlled by just a single locus. This criticism, however, is not well founded. First, if one considers the evolution of continuous or probabilistically expressed traits (Box 6.1), where one looks at the repeated invasion of mutants of small effect, then although each invasion event would consider the spread of a single allele at a single locus, the wild type in each case could be controlled by any number of loci. In addition, in recent years, there has been a tendency to define $g$, as in quantitative genetics, as the breeding value (additive genetic value) for a given trait, which is a linear combination of the frequency of any number of alleles at any number of loci that best predicts an individual's phenotype (Falconer 1981, Crow \& Aoki 1982, Frank 1998). Either way, it is not assumed that social traits are under the control of a single locus.

A fully general and more explicit multilocus social evolution theory was recently also developed by Billiard and Lenormand (2005), Roze and Rousset $(2005,2008)$ and Gardner et al. (2007), based on the multilocus methodology of Barton and Turelli (1991) and Kirkpatrick et al. (2002). This theory, which was formulated from a neighbour-modulated fitness perspective, takes explicit account of the fact that the natural selection operating upon one genetic locus can potentially spill over onto associated loci and indirectly drive changes in gene frequencies. Within the multilocus framework, such genetic hitchhiking is measured by the association between genes within individuals (i.e. linkage disequilibrium), and relatedness arises in a similar way as the association between genes in different individuals (Gardner et al. 2007). These methods are important, as they allow the coevolution between different traits in the same or in different sets of individuals (e.g. parents and offspring) to be examined, taking explicit account of the fact that some of the genes involved in the traits may be linked, and taking account of any type of non-additive gene interaction (dominance or epistasis). When selection is weak and the genes for the different traits are unlinked, however, coevolutionary problems may also be analysed more simply using the maximisation methods discussed in Box 6.1 (see Frank 1995b).

\subsubsection{Complex demographies and spatially explicit models}

A frequent complication is that social interactions do not occur within family groups that reform in each generation, but instead occur locally among individuals 
that tend to stay near their natal patch. Hamilton (1964, 1972) suggested that such population viscosity could favour cooperation because limited dispersal would result in interacting individuals tending to be relatives. However, Wilson et al. (1992) later showed, using an explicitly spatial cellular automaton model, that in a simple-case scenario this argument does not hold. The reason is that limited dispersal also results in local competition, the consequence of which is that patches of altruists would be unable to export their higher productivity to the rest of the population. In the model of Wilson et al. (1992) these two factors exactly cancelled, so that population viscosity had negligible influence on the evolution of cooperation. The same year, Taylor was also able to confirm analytically, using a kin-selection approach, that the effect of increased competition between relatives exactly cancels out with the effect of increased relatedness if the spatial scale of competition is the same as the spatial scale of dispersal (Taylor 1992, reviewed by Queller 1992c, West et al. 2002). Since then, a number of theoretical models have examined the extent to which more complex and possibly biologically realistic assumptions can reduce the problem of local competition, and lead to limited dispersal favouring altruism (Kelly 1992, 1994, van Baalen \& Rand 1998, Mitteldorf \& Wilson 2000, Taylor \& Irwin 2000, Gardner \&West 2006, Lehmann etal. 2006, 2008a). For example, Gardner and West (2006) and Lehmann et al. (2006) show that the effect of local competition can be partly overcome if individuals disperse in groups or buds, while van Baalen and Rand (1998) also show how the invasion condition for a small cluster of altruists in a cellular automata-type model reduces to a form of Hamilton's rule. Recent analyses using evolutionary graph theory, whereby individuals interact in social networks (Chapter 9; Ohtsuki et al. 2006, Ohtsuki \& Nowak 2006), have been shown to similarly fall under the remit of inclusive fitness theory (Grafen 2007b, Lehmann et al. 2007b, Taylor et al. 2007b).

Typical for most models involving complex demographies is that relatedness is not just a fixed genetic parameter, but instead depends on population demographic processes such as migration and birth/death dynamics (Taylor 1992, van Baalen \& Rand 1998, Gardner \& West 2006, Lehmann et al. 2006). Taylor et al. $(2007 \mathrm{c})$ present a recursive method for calculating relatedness as a function of population demographic parameters, and Rousset (2004) also presents general methods for analysing inclusive fitness models under complex population demographies.

\subsubsection{Social and individual learning}

In some situations, particularly in humans (Chapter 15), it is likely that social traits are not purely genetically determined but are also affected by norms and beliefs that are culturally transmitted through imitation and social learning (Cavalli-Sforza \& Feldman 1981, Boyd \& Richerson 1985). Dawkins, by analogy with genes, refers to such cultural beliefs as memes (Dawkins 1976), and they may be either discrete in nature (e.g. whether or not one advocates a particular religion) or continuously varying traits (e.g. hunting skill: Boyd \& Richerson 1985, Henrich 2004). Using the above methods, the spread of cultural beliefs can be modelled in much the same way as the spread of genes within populations, although there are some important qualifications. First, biological fitness $(w)$ is usually redefined as cultural fitness, which is the extent to which an individual can affect the proportional representation of a cultural trait in the next generation or time step (Henrich 2004). Second, mutation sometimes requires to be taken into account, since cultural traits are liable to mutate and change at a much faster rate than genes. This can be done by retaining the transmission bias term of the Price equation (equation 6.1; for an example see Frank 1998, p. 55).

Models of cultural evolution have been constructed within both the group-selection and inclusive-fitness traditions. From a group-selection perspective, it has been noted that in cultural evolution among-group differences tend to be much larger than in genetic models, since individuals that migrate to other groups are frequently forced to adopt the customs and norms of the group they join (conformist transmission: Boyd \& Richerson 1985, Henrich 2004). This can favour cooperative behaviour via cultural group selection (Boyd et al. 2003, reviewed in Henrich 2004), although it is an open question as to whether cultural transmission will in general promote or hinder cooperation relative to genetic transmission (Lehmann et al. 2008b, 2008c). 
From an inclusive fitness perspective, Allison (1992) noted that the concept of genetic relatedness can be readily extended to cultural relatedness, which is defined as the likelihood that two interacting individuals are more likely than chance to share the same cultural belief. Allison (1992) showed that if cultural beliefs are copied from a limited set of individuals in the group (e.g. a tribal chief), as would be the case in conformist transmission, cultural relatedness can be very high, and that this could promote cooperation (see also Lehmann et al. 2007c). Using recurrence equations, equilibrium levels of cultural relatedness under various vertical, oblique and horizontal transmission schemes were also provided. Clearly, the inclusive-fitness optimisation method may well be a promising approach for gaining a better understanding of cultural evolution, particularly if cultural change occurs relatively slowly (i.e. if cultural variants have small effects and mutate slowly). The notion of reproductive value would also be readily applicable, given that human groups generally contain different classes of individuals (e.g. leaders and followers, teachers and students) that have a different influence in causing future cultural change. When cultural variants have large effects, however, it may be easier to resort to a traditional population-genetic approach (Cavalli-Sforza \& Feldman, 1981, Boyd \& Richerson 1985, Feldman et al. 1985).

While models of the social learning of culture bring added realism to social evolution in humans and derived vertebrates, they tend, like genetic models, to assume that individuals inherit simple and relatively fixed strategies by cultural means. Many economists, however, instead emphasise the impressive ability of humans to modify their social behaviours by trial-and-error learning or reasoning (Rubinstein 1998). Such individual learning can again be modelled using evolutionary logic. Nevertheless, the full impact of incorporating individual learning into genetic and cultural models remains to be determined (Lehmann et al. 2008c).

\subsection{Conclusions and future directions}

Close to 50 years after Hamilton's seminal papers (1963, 1964), the evolution of cooperation and altruism remains one of the most active areas of study in evolutionary biology. Indeed, it is considered to be one of the most important unsolved questions in science (Pennisi 2005). This is not to say we have not made great progress already. The available methods now allow complex demographies to be analysed (Taylor 1992, Rousset 2004, Lehmann et al. 2006, Gardner \& West 2006), spatial, age and sex structure to be explicitly incorporated (Taylor \& Frank 1996, van Baalen \& Rand 1998, Lehmann \& Keller 2006a, Lehmann et al. 2007b, Grafen 2007b, Taylor et al. 2007a, 2007b), the effects of synergy and frequency dependence to be assessed (Queller 1984, Wenseleers 2006, Lehmann \& Keller 2006b, Gardner et al. 2007), multilocus and non-additive genetics to be incorporated (Billiard \& Lenormand 2005, Roze \& Rousset 2005, 2008, Gardner et al. 2007), the conditions to be determined under which disruptive selection and evolutionary branching will occur (Taylor 1996, Doebeli et al. 2004), and cultural evolution to be analysed in much the same way as genetic evolution (Allison 1992, Frank 1997b, Henrich 2004, Lehmann et al. 2007c). In addition, results can often be obtained in equivalent ways within the frameworks of neighbour-modulated fitness, inclusive fitness or levels of selection.

Nevertheless, important challenges remain. For example, many of the derivations require weak selection (e.g. in the calculation of reproductive value, relatedness and between- and within-group genetic variances), inclusive fitness theory requires strategic equivalence (i.e. all actors being equivalent: Grafen 2006), and better methods to deal with frequency dependence in inclusive fitness models remain to be developed (Wenseleers 2006, Grafen 2006, 2007a). Levels-of-selection approaches still suffer from semantic difficulties that would be desirable to fix (Okasha 2006, Wilson \& Wilson 2007), and as yet they struggle somewhat to properly incorporate class structure (West et al. 2008). Lastly, much work remains to be done on cultural evolution (Cavalli-Sforza \& Feldman 1981, Boyd \& Richerson 1985, Lehmann et al. 2007c). It is clear that social evolution theory will remain a fruitful topic for years to come.

\section{Acknowledgements}

We thank the FWO-Flanders (TW), the Royal Society (AG) and the National Institute of General Medical 
Sciences Center of Excellence (KRF) for financial support.

\section{Suggested readings}

Frank, S. A. (1998) The Foundations of Social Evolution. Princeton, NJ: Princeton University Press.

Kokko, H. (2007) Modelling for Field Biologists and other Interesting People. Cambridge: Cambridge University Press.

McElreath, R. \& Boyd, R. (2007) Mathematical Models of Social Evolution: a Guide for the Perplexed. Chicago, IL: University of Chicago Press.

Okasha, S. (2006) Evolution and the Levels of Selection. Oxford: Oxford University Press.

Rousset, F. (2004) Genetic Structure and Selection in Subdivided Populations. Princeton, NJ: Princeton University Press.

\section{References}

Allison, P. D. (1992) Cultural relatedness under oblique and horizontal transmission rules. Ethology and Sociobiology, 13, 153-169.

Andersen, E. S. (2004) Population thinking, Price's equation and the analysis of economic evolution. Evolutionary and Institutional Economics Review, 1, 127-148.

Arnold, A. J. \& Fristrup, K. (1982) The theory of evolution by natural selection: a hierarchical expansion. Paleobiology, $\mathbf{8}$, 113-129.

Axelrod, R. \& Hamilton, W. D. (1981) The evolution of cooperation. Science, 211, 1390-1396.

Axelrod, R., Hammond, R. A. \& Grafen, A. (2004) Altruism via kin-selection strategies that rely on arbitrary tags with which they coevolve. Evolution, 58, 1833-1838.

Barton, N. H. \& Turelli, M. (1991) Natural and sexual selection on many loci. Genetics, 127, 229-255.

Bijma, P. \& Wade, M. J. (2008) The joint effects of kin, multilevel selection and indirect genetic effects on response to genetic selection. Journal of Evolutionary Biology, 21, 1175-1188.

Billiard, S. \& Lenormand, T. (2005) Evolution of migration under kin selection and local adaptation. Evolution, 59, 13-23.

Bourke, A. F. G. (1988) Worker reproduction in the higher eusocial Hymenoptera. Quarterly Review of Biology, 63, 291-311.

Bourke, A. F. G. \& Franks, N. R. (1995) Social Evolution in Ants. Princeton, NJ: Princeton University Press.

Boyd, R. \& Richerson, P. J. (1985) Culture and the Evolutionary Process. Chicago, IL: University of Chicago Press.
Boyd, R., Gintis, H., Bowles, S. \& Richerson, P. J. (2003) The evolution of altruistic punishment. Proceedings of the National Academy of Sciences of the USA, 100, 3531-3535.

Breden, F. (1990) Partitioning of covariance as a method for studying kin selection. Trends in Ecology and Evolution, 5, 224-228.

Bulmer, M. (1994) Theoretical Evolutionary Ecology. Sunderland, MA: Sinauer Associates.

Cavalli-Sforza, L. L. \& Feldman, M. W. (1978) Darwinian selection and altruism. Theoretical Population Biology, 14, 268-280.

Cavalli-Sforza, L. L. \& Feldman, M. W. (1981) Cultural Transmission and Evolution. Princeton, NJ: Princeton University Press.

Charlesworth, B. \& Charnov, E. L. (1981) Kin selection in agestructured populations. Journal of Theoretical Biology, 88, 103-119.

Charnov, E. L. (1978) Evolution of eusocial behavior: offspring choice or parental parasitism? Journal of Theoretical Biology, 75, 451-465.

Christiansen, F. B. (1991) On conditions for evolutionary stability for a continuously varying character. American Naturalist, 138, 37-50.

Colwell, R. K. (1981) Group selection is implicated in the evolution of female biased sex ratios. Nature, 290, 401-404.

Craig, J. V. \& Muir, W. M. (1996) Group selection for adaptation to multiple-hen cages: behavioral responses. Poultry Science, 75, 1145-1155.

Crow, J. F. \& Aoki, K. (1982) Group selection for a polygenic behavioral trait: a differential proliferation model. Proceedings of the National Academy of Sciences of the USA, 79, 2628-2631.

Darwin, C. (1859) On the Origin of Species by Means of Natural Selection. London: John Murray.

Dawkins, R. (1976) The Selfish Gene. Oxford: Oxford University Press.

Day, T. (2001) Population structure inhibits evolutionary diversification under competition for resources. Genetica, 112/113, 71-86.

Day, T. \& Gandon, S. (2007) Applying population-genetic models in theoretical evolutionary epidemiology. Ecology Letters, 10, 876-888.

Doebeli, M., Hauert, C. \& Killingback, T. (2004) The evolutionary origin of cooperators and defectors. Science, 306, 859-862.

Dugatkin, L. A. \& Reeve, H. K. (1994) Behavioral ecology and levels of selection - Dissolving the group selection controversy. Advances in the Study of Behavior, 23, 101-133. 
Eshel, I. (1983) Evolutionary and continuous stability. Journal of Theoretical Biology, 103, 99-111.

Eshel, I. \& Cavalli-Sforza, L. L. (1982) Assortment of encounters and evolution of cooperativeness. Proceedings of the National Academy of Sciences of the USA, 79, 1331-1335.

Eshel, I. \& Motro, U. (1981) Kin selection and strong evolutionary stability of mutual help. Theoretical Population Biology, 19, 420-433.

Falconer, D. S. (1981) Introduction to Quantitative Genetics, 2nd edn. London: Longman.

Fehr, E. \& Fischbacher, U. (2003) The nature of human altruism. Nature, 425, 785-791.

Feldman, M. W. \& Cavalli-Sforza, L. L. (1981) Further remarks on Darwinian selection and altruism. Theoretical Population Biology, 19, 251-260.

Feldman, M. W., Cavalli-Sforza, L. L. \& Peck, J. R. (1985) Gene-culture coevolution: models for the evolution of altruism with cultural transmission. Proceedings of the National Academy of Sciences of the USA, 82, 5814-5818.

Fisher, R. A. (1930) The Genetical Theory of Natural Selection. Oxford: Clarendon Press.

Fletcher, J. A. \& Doebeli, M. (2006) How altruism evolves: assortment and synergy. Journal of Evolutionary Biology, 19, 1389-1393.

Fletcher, J. A. \& Zwick, M. (2006) Unifying the theories of inclusive fitness and reciprocal altruism. American Naturalist, 168, 252-262.

Foster, K. R. (2004) Diminishing returns in social evolution: the not-so-tragic commons. Journal of Evolutionary Biology, 17, 1058-1072.

Foster, K. R. (2006) Balancing synthesis with pluralism in sociobiology. Journal of Evolutionary Biology, 19, 1394-1396.

Foster, K. R. \& Wenseleers, T. (2006) A general model for the evolution of mutualisms. Journal of Evolutionary Biology, 19, 1283-1293.

Foster, K. R., Wenseleers, T., Ratnieks, F. L. W. \& Queller, D. C. (2006a) There is nothing wrong with inclusive fitness. Trends in Ecology and Evolution, 21, 599-560.

Foster, K. R., Wenseleers, T. \& Ratnieks, F. L. W. (2006b) Kin selection is the key to altruism. Trends in Ecology and Evolution, 21, 57-60.

Fox, J. W. (2006) Using the Price Equation to partition the effects of biodiversity loss on ecosystem function Ecology, 87, 2687-2696.

Frank, S. A. (1986) Hierarchical selection theory and sex-ratios. 1. General solutions for structured populations. Theoretical Population Biology, 29, 312-342.
Frank, S. A. (1994a) Genetics of mutualism: the evolution of altruism between species. Journal of Theoretical Biology, 170, 393-400.

Frank, S. A. (1994b) Kin selection and virulence in the evolution of protocells and parasites. Proceedings of the Royal Society B, 258, 153-161.

Frank, S. A. (1995a) George Price's contributions to evolutionary genetics. Journal of Theoretical Biology, 175, 373-388.

Frank, S. A. (1995b) Mutual policing and repression of competition in the evolution of cooperative groups. Nature, $\mathbf{3 7 7}$, 520-522.

Frank, S. A. (1997a) Multivariate analysis of correlated selection and kin selection, with an ESS maximization method. Journal of Theoretical Biology, 189, 307-316.

Frank, S. A. (1997b) The Price equation, Fisher's fundamental theorem, kin selection, and causal analysis. Evolution, 51, 1712-1729.

Frank, S. A. (1998) The Foundations of Social Evolution. Princeton, NJ: Princeton University Press.

Gandon, S. (1999) Kin competition, the cost of inbreeding and the evolution of dispersal. Journal of Theoretical Biology, 200, 345-364.

Gardner, A. \& Foster, K. R. (2008) The evolution and ecology of cooperation: history and concepts. In: Ecology of Social Evolution, ed. J. Korb \& J. Heinze. Berlin, Heidelberg: Springer, pp. 1-36.

Gardner, A. \& Grafen, A. (2009) Capturing the superorganism: a formal theory of group adaptation. Journal of Evolutionary Biology 22, 659-671.

Gardner, A. \& West, S. A. (2004) Cooperation and punishment, especially in humans. American Naturalist, 164, 753-764.

Gardner, A. \& West, S. A. (2006) Demography, altruism, and the benefits of budding. Journal of Evolutionary Biology, 19, 1707-1716.

Gardner, A. \& West, S. A. (2010) Greenbeards. Evolution, 64, 25-38.

Gardner, A., West, S. A. \& Barton, N. H. (2007) The relation between multilocus population genetics and social evolution theory. American Naturalist, 169, 207-226.

Gayley, T. (1993) Genetics of kin selection: the role of behavioral inclusive fitness. American Naturalist, 141, 928-953.

Geritz, S. A. H., Kisdi, E., Meszéna, G. \& Metz, J. A. J. (1998) Evolutionarily singular strategies and the adaptive growth and branching of the evolutionary tree. Evolutionary Ecology, 12, 35-57.

Gintis, H. (2000a) Strong reciprocity and human sociality. Journal of Theoretical Biology, 206, 169-179. 
Gintis, H. (2000b) Game Theory Evolving: A Problem-Centered Introduction to Modelling Strategic Interaction. Princeton, New Jersey: Princeton University Press.

Gintis, H., Bowles, S., Boyd, R. \& Fehr, E. (2003) Explaining altruistic behavior in humans. Evolution and Human Behavior, 24, 153-172.

Gintis, H., Bowles, S., Boyd, R. T. \& Fehr, E. (2005) Moral Sentiments and Material Interests: the Foundations of Cooperation in Economic Life. Cambridge, MA: MIT Press.

Goodnight, C. J., Schwartz, J. M. \& Stevens, L. (1992) Contextual analysis of models of group selection, soft selection, hard selection, and the evolution of altruism. American Naturalist, 140, 743-761.

Grafen, A. (1979) The hawk-dove game played between relatives. Animal Behaviour, 27, 905-907.

Grafen, A. (1985) A geometric view of relatedness. Oxford Surveys in Evolutionary Biology, 2, 28-89.

Grafen, A. (2006) Optimization of inclusive fitness. Journal of Theoretical Biology, 238, 541-563.

Grafen, A. (2007a) The formal Darwinism project: a mid-term report. Journal of Evolutionary Biology, 20, 1243-1254.

Grafen, A. (2007b) An inclusive fitness analysis of altruism on a cyclical network. Journal of Evolutionary Biology, 20, 2278-2283.

Griffin, A. S. \& West, S. A. (2002) Kin selection: fact and fiction. Trends in Ecology and Evolution, 17, 15-21.

Griffin, A. S. \& West, S. A. (2003) Kin discrimination and the benefit of helping in cooperatively breeding vertebrates. Science, 302, 634-636.

Hamilton, W. D. (1963) The evolution of altruistic behaviour. American Naturalist, 97, 354-356.

Hamilton, W. D. (1964) The genetical evolution of social behaviour, I \& II. Journal of Theoretical Biology, 7, 1-52.

Hamilton, W. D. (1970) Selfish and spiteful behaviour in an evolutionary model. Nature, 228, 1218-1220.

Hamilton, W. D. (1972) Altruism and related phenomena, mainly in social insects. Annual Review of Ecology and Systematics, 3, 193-232.

Hamilton, W. D. (1975) Innate social aptitudes in man: an approach from evolutionary genetics. In: Biosocial Anthropology, ed. R. Fox. New York, NY: Wiley, pp. 133-155.

Hamilton, W. D. (1995) Narrow Roads of Gene Land. Volume 1. Evolution of Social Behaviour. New York, NY: W.H. Freeman.

Hardin, G. (1968) The tragedy of the commons. Science, $\mathbf{1 6 2}$ 1243-1244.
Heisler, I. L. \& Damuth, J. (1987) A method for analyzing selection in hierarchically structured populations. American Naturalist, 130, 582-602.

Henrich, J. (2004) Cultural group selection, coevolutionary processes and large-scale cooperation. Journal of Economic Behavior and Organization, 53, 3-35.

Keller, L. (1999) Levels of Selection in Evolution. Princeton, NJ: Princeton University Press.

Kelly, J. K. (1992) Restricted migration and the evolution of altruism. Evolution, 46, 1492-1495.

Kelly, J. K. (1994) The effect of scale dependent processes on kin selection: mating and density regulation. Theoretical Population Biology, 46, 32-57.

Kirkpatrick, M., Johnson, T. \& Barton, N. H. (2002) General models of multilocus evolution. Genetics, 161, 1727-1750.

Kokko, H. (2007) Modelling for Field Biologists (and Other Interesting People). Cambridge: Cambridge University Press.

Lehmann, L. \& Keller, L. (2006a) The evolution of cooperation and altruism: a general framework and a classification of models. Journal of Evolutionary Biology, 19, 1365-1376.

Lehmann, L. \& Keller, L. (2006b) Synergy, partner choice and frequency dependence: their integration into inclusive fitness theory and their interpretation in terms of direct and indirect fitness effects. Journal of Evolutionary Biology, 19, 1426-1436.

Lehmann, L., Perrin, N. \& Rousset, F. (2006) Population demography and the evolution of helping behaviors. Evolution, 60, 1137-1151.

Lehmann, L., Keller, L., West, S. \& Roze, D. (2007a) Group selection and kin selection: two concepts but one process. Proceedings of the National Academy of Sciences of the USA, 104, 6736-6739.

Lehmann, L., Keller, L. \& Sumpter, D. J. T. (2007b) The evolution of helping and harming on graphs: the return of the inclusive fitness effect. Journal of Evolutionary Biology, 20, 2284-2295

Lehmann, L., Rousset, F., Roze, D. \& Keller, L. (2007c) Strong reciprocity or strong ferocity? A population genetic view of the evolution of altruistic punishment. American Naturalist, 170, 21-36.

Lehmann, L., Ravigne, V. \& Keller, L. (2008a) Population viscosity can promote the evolution of altruistic sterile helpers and eusociality. Proceedings of the Royal Society B, 275, 1887-1895. 
Lehmann, L., Feldman, M. W. \& Foster, K. R. (2008b) Cultural transmission can inhibit the evolution of altruistic helping. American Naturalist, 172, 12-24.

Lehmann, L., Foster, K. R., Borenstein, E. \& Feldman, M. W. (2008c) Social and individual learning of helping in humans. Trends in Ecology and Evolution, 23, 664-671.

Leigh, E. G. (1983) When does the good of the group override the advantage of the individual? Proceedings of the National Academy of Sciences of the USA, 80, 2985-2989.

Leturque, H. \& Rousset, F. (2003) Joint evolution of sex ratio and dispersal: Conditions for higher dispersal rates from good habitats. Evolutionary Ecology, 17, 67-84.

Loreau, M. \& Hector, A. (2001) Partitioning selection and complementarity in biodiversity experiments. Nature, 412, $72-76$.

Maynard Smith, J. (1964) Group selection and kin selection. Nature, 201, 1145-1147.

Maynard Smith, J. (1982) Evolution and the Theory of Games. Cambridge: Cambridge University Press.

McElreath, R. \& Boyd, R. (2007) Mathematical Models of Social Evolution: a Guide for the Perplexed. Chicago, IL: University of Chicago Press.

Metz, J. A. J., Nisbet, R. \& Geritz, S. A. H. (1992) How should we define 'fitness' for general ecological scenarios? Trends in Ecology and Evolution, 7, 198-202.

Michod, R. E. (1999) Darwinian Dynamics: Evolutionary Transitions in Fitness and Individuality. Princeton, NJ: Princeton University Press.

Michod, R. E. \& Hamilton, W. D. (1980) Coefficients of relatedness in sociobiology. Nature, 288, 694-697.

Mitteldorf, J. \& Wilson, D. S. (2000) Population viscosity and the evolution of altruism. Journal of Theoretical Biology, 204, 481-496.

Muir, W. M. (1996) Group selection for adaptation to multiplehen cages: selection program and direct responses. Poultry Science, 75, 447-458.

Muir, W. M. (2005) Incorporation of competitive effects in forest tree or animal breeding programs. Genetics, 170, 1247-1259.

Nee, S. (1989) Does Hamilton's rule describe the evolution of reciprocal altruism? Journal of Theoretical Biology, 141, 81-91.

Nowak, M. A. (2006) Five rules for the evolution of cooperation. Science, 314, 1560-1563.

Nowak, M. A. \& Sigmund, K. (1998) Evolution of indirect reciprocity by image scoring. Nature, 393, 573-577.

Ohtsuki, H. \& Nowak, M. A. (2006) Evolutionary games on cycles. Proceedings of the Royal Society B, 273, 2249-2256.
Ohtsuki, H., Hauert, C., Lieberman, E. \& Nowak, M. A. (2006) A simple rule for the evolution of cooperation on graphs and social networks. Nature, 441, 502-505.

Okasha, S. (2006) Evolution and the Levels of Selection. Oxford: Oxford University Press.

Orlove, M. J. \& Wood, C. L. (1978) Coefficients of relationship and coefficients of relatedness in kin selection: covariance form for the Rho formula. Journal of Theoretical Biology, 73, 679-686.

Otto, S. P. \& Day, T. (2007) A Biologist's Guide to Mathematical Modeling in Ecology and Evolution. Princeton, NJ: Princeton University Press.

Page, K. M. \& Nowak, M. A. (2002) Unifying evolutionary dynamics. Journal of Theoretical Biology, 219, 93-98.

Pamilo, P. (1991) Evolution of colony characteristics in social insects 1. Sex allocation. American Naturalist, 137, 83-107.

Parvinen, K. (2005) Evolutionary suicide. Acta Biotheoretica, 53, 241-264.

Pen, I. (2006) When boys want to be girls: effects of mating system and dispersal on parent-offspring sex ratio conflict. Evolutionary Ecology Research, 8, 103-113.

Pennisi, E. (2005) How did cooperative behavior evolve? Science, 309, 93.

Pepper, J. W. (2000) Relatedness in trait group models of social evolution. Journal of Theoretical Biology, 206, 355-368.

Price, G. R. (1970) Selection and covariance. Nature, 227, 520-521.

Price, G. R. (1972) Extension of covariance selection mathematics. Annals of Human Genetics, 35, 455-458.

Price, G. R. (1995) The nature of selection. Journal of Theoretical Biology, 175, 389-396 [written circa 1971].

Queller, D. C. (1984) Kin selection and frequency-dependence: a game theoretic approach. Biological Journal of the Linnean Society, 23, 133-143.

Queller, D. C. (1985) Kinship, reciprocity and synergism in the evolution of social behaviour. Nature, 318, 366-367.

Queller, D. C. (1992a) Quantitative genetics, inclusive fitness, and group selection. American Naturalist, 139, 540-558.

Queller, D. C. (1992b) A general model for kin selection. Evolution, 46, 376-380.

Queller, D. C. (1992c) Does population viscosity promote kin selection? Trends in Ecology and Evolution, 7, 322-324.

Rankin, D. J. (2007) Resolving the tragedy of the commons: the feedback between intraspecific conflict and population density. Journal of Evolutionary Biology, 20, 173-180.

Rankin, D. J. \& López-Sepulcre, A. (2005) Can adaptation lead to extinction? Oikos, 111, 616-619. 
Rankin, D. J., López-Sepulcre, A., Foster, K. R. \& Kokko, H. (2007) Species-level selection reduces selfishness through competitive exclusion. Journal of Evolutionary Biology, 20, 1459-1468.

Ratnieks, F. L. W. \& Reeve, H. K. (1992) Conflict in single-queen hymenopteran societies: the structure of conflict and processes that reduce conflict in advanced eusocial species. Journal of Theoretical Biology, 158, 33-65.

Ratnieks, F. L. W. \& Wenseleers, T. (2008) Altruism in insect societies and beyond: voluntary or enforced? Trends in Ecology and Evolution, 23, 45-52.

Ratnieks, F. L. W., Foster, K. R. \& Wenseleers, T. (2006) Conflict resolution in insect societies. Annual Review of Entomology, 51, 581-608.

Rice, S. H. (2004) Evolutionary Theory: Mathematical and Conceptual Foundations. Sunderland, MA: Sinauer Associates.

Robertson, A. (1966) A mathematical model of the culling process in dairy cattle. Animal Production, 8, 95-108.

Robertson, A. (1968) The spectrum of genetic variation. In: Population Biology and Evolution, ed. R. C. Lewontin. Syracuse, NY: Syracuse University Press, pp. 5-16.

Ross-Gillespie, A., Gardner, A., West, S. A. \& Griffin, A. S. (2007) Frequency dependence and cooperation: theory and a test with bacteria. American Naturalist, 170, 331-342.

Rousset, F. (2004) Genetic Structure and Selection in Subdivided Populations. Princeton, NJ: Princeton University Press.

Rousset, F. (2006) Separation of time scales, fixation probabilities and convergence to evolutionarily stable states under isolation by distance. Theoretical Population Biology, 69, 165-179.

Roze, D. \& Rousset, F. (2005) Inbreeding depression and the evolution of dispersal rates: a multilocus model. American Naturalist, 166, 708-721.

Roze, D. \& Rousset, F. (2008) Multilocus models in the infinite island model of population structure. Theoretical Population Biology, 73, 529-542.

Rubinstein, A. (1998) Modeling Bounded Rationality. Cambridge, MA: MIT Press.

Skyrms, B. (1996) Evolution of the Social Contract. Cambridge: Cambridge University Press.

Sober, E. \& Wilson, D. S. (1998) Unto Others: the Evolution of Altruism. Cambridge, MA.: Harvard University Press.

Strassmann, J. E. \& Queller, D. C. (2007) Altruism among amoebas. Natural History, 116, 24-29.

Suzuki, Y. \& Toquenaga, Y. (2005) Effects of information and group structure on evolution of altruism: analysis of twoscore model by covariance and contextual analyses. Journal of Theoretical Biology, 232, 191-201.
Swenson, W., Wilson, D. S. \& Elias, R. (2000) Artificial ecosystem selection. Proceedings of the National Academy of Sciences of the USA, 97, 9110-9114.

Taylor, C. \& Nowak, M. A. (2007) Transforming the dilemma. Evolution, 61, 2281-2292.

Taylor, P. D. (1990) Allele-frequency change in a class-structured population. American Naturalist, 135, 95-106.

Taylor, P. D. (1992) Altruism in viscous populations: an inclusive fitness model. Evolutionary Ecology, 6, 352-356.

Taylor, P. D. (1996) Inclusive fitness arguments in genetic models of behaviour. Journal of Mathematical Biology, 34, 654-674.

Taylor, P. D. \& Frank, S. A. (1996) How to make a kin selection model. Journal of Theoretical Biology, 180, 27-37.

Taylor, P. D. \& Irwin, A. J. (2000) Overlapping generations can promote altruistic behavior. Evolution, 54, 1135-1141.

Taylor, P. D., Wild, G. \& Gardner, A. (2007a) Direct fitness or inclusive fitness: how shall we model kin selection? Journal of Evolutionary Biology, 20, 301-309.

Taylor, P. D., Day, T. \& Wild, G. (2007b) Evolution of cooperation in a finite homogeneous graph. Nature, 447, 469-472.

Taylor, P. D., Day, T. \& Wild, G. (2007c) From inclusive fitness to fixation probability in homogeneous structured populations. Journal of Theoretical Biology, 249, 101-110.

Traulsen, A. \& Nowak, M. A. (2006) Evolution of cooperation by multilevel selection. Proceedings of the National Academy of Sciences of the USA, 103, 10952-10955.

Traulsen, A. \& Schuster, H. G. (2003) Minimal model for tagbased cooperation. Physical Review E, 68, 046129.

Trivers, R. L. (1971) The evolution of reciprocal altruism. Quarterly Review of Biology, 46, 35-57.

Uyenoyama, M. \& Feldman, M. W. (1980) Theories of kin and group selection: a population genetics perspective. Theoretical Population Biology, 17, 380-414.

Van Baalen, M. \& Rand, D. A. (1998) The unit of selection in viscous populations and the evolution of altruism. Journal of Theoretical Biology, 193, 631-648.

Wade, M. J. (1976) Group selection among laboratory populations of Tribolium. Proceedings of the National Academy of Sciences of the USA, 73, 4604-4607.

Wade, M. J. (1977) An experimental study of group selection. Evolution, 31, 134-153.

Wade, M. J. (1980) Kin selection: its components. Science, 210, 665-667.

Wade, M. J. \& Goodnight, C. J. (1998) Perspective. The theories of Fisher and Wright in the context of metapopulations: when nature does many small experiments. Evolution, 52, 1537-1553. 
Wenseleers, T. (2006) Modelling social evolution: the relative merits and limitations of a Hamilton's rule-based approach. Journal of Evolutionary Biology, 19, 1419-1422.

Wenseleers, T. \& Ratnieks, F. L. W. (2004) Tragedy of the commons in Melipona bees. Proceedings of the Royal Society B, 271, S310-312.

Wenseleers, T. \& Ratnieks, F. L. W. (2006a) Comparative analysis of worker reproduction and policing in eusocial Hymenoptera supports relatedness theory. American Naturalist, 168, E163-E179.

Wenseleers, T. \& Ratnieks, F. L. W. (2006b) Enforced altruism in insect societies. Nature, 444, 50 .

Wenseleers, T., Ratnieks, F. L. W. \& Billen, J. (2003) Caste fate conflict in swarm-founding social Hymenoptera: an inclusive fitness analysis. Journal of Evolutionary Biology, 16, 647-658.

Wenseleers, T., Hart, A. G. \& Ratnieks, F. L. W. (2004a) When resistance is useless: Policing and the evolution of reproductive acquiescence in insect societies. American Naturalist, 164, E154-E167.

Wenseleers, T., Helanterä, H., Hart, A. G. \& Ratnieks, F. L. W. (2004b) Worker reproduction and policing in insect societies: an ESS analysis. Journal of Evolutionary Biology, 17, 1035-1047.

West, S. A., Pen, I. \& Griffin, A. S. (2002) Cooperation and competition between relatives. Science, 296, 72-75.

West, S. A., Griffin, A. S. \& Gardner, A. (2007a) Evolutionary explanations for cooperation. Current Biology, 17, R661-672.

West, S. A., Griffin, A. S. \& Gardner, A. (2007b) Social semantics: altruism, cooperation, mutualism, strong reciprocity and group selection. Journal of Evolutionary Biology, 20, 415-432.

West, S. A., Griffin, A. S. \& Gardner, A. (2008) Social semantics: how useful has group selection been? Journal of Evolutionary Biology, 21, 374-385.

Wild, G. \& Taylor, P. D. (2005) A kin-selection approach to the resolution of sex-ratio conflict between mates. Journal of Theoretical Biology, 236, 126-136.
Williams, G. C. \& Williams, D. C. (1957) Natural selection of individually harmful social adaptations among sibs with special reference to social insects. Evolution, 11, 32-39.

Wilson, D. S. (1975) A theory of group selection. Proceedings of the National Academy of Sciences of the USA, 72, 143-146.

Wilson, D. S. (1983) The group selection controversy: history and current status. Annual Review of Ecology and Systematics, 14, 159-187.

Wilson, D. S. (1990) Weak altruism, strong group selection. Oikos, 59, 135-140.

Wilson, D. S. (1997) Biological communities as functionally organized units. Ecology, 78, 2018-2024.

Wilson, D. S. (2008) Social semantics: toward a genuine pluralism in the study of social behaviour. Journal of Evolutionary Biology, 21, 368-373.

Wilson, D. S. \& Colwell, R. K. (1981) Evolution of sex-ratio in structured demes. Evolution, 35, 882-897.

Wilson, D. S. \& Sober, E. (1989) Reviving the Superorganism. Journal of Theoretical Biology, 136, 337-356.

Wilson, D. S. \& Wilson, E. O. (2007) Rethinking the theoretical foundation of sociobiology. Quarterly Review of Biology, 82, 327-348.

Wilson, D. S., Pollock, G. B. \& Dugatkin, L. A. (1992) Can altruism evolve in purely viscous populations? Evolutionary Ecology, 6, 331-341.

Wilson, E. O. \& Hölldobler, B. (2005) Eusociality: origin and consequences. Proceedings of the National Academy of Sciences of the USA, 102, 13367-13371.

Wolf, J. B., Brodie, E. D. \& Moore, A. J. (1999) Interacting phenotypes and the evolutionary process. II. Selection resulting from social interactions. American Naturalist, 153, 254-266.

Wright, S. (1945) Tempo and mode in evolution: a critical review. Ecology, 26, 415-419.

Wright, S. (1951) The genetical structure of populations. Annals of Eugenics, 15, 323-354.

Yang, R. C. (1998) Estimating hierarchical F-statistics. Evolution, 52, 950-956. 